\title{
GESTÃO DE ÁGUA NA IRRIGAÇÃO E MODIFICAÇÕES NA COBERTURA DO SOLO EM RESERVATÓRIO ARTIFICIAL NO SEMIÁRIDO BRASILEIRO
}

\section{Patrício Rinaldo dos Santos}

Universidade Federal de Pernambuco (UFPE)

Recife - Pernambuco - Brasil

E-mail: patricioibimirim@hotmail.com Orcid: https://orcid.org/0000-0002-75114788

\section{Breno Leonan de Carvalho Lima}

Instituto Nacional do Semiárido (INSA)

Campina Grande - Paraíba - Brasil

E-mail: breno.Iclima@gmail.com

Orcid: https://orcid.org/0000-0001-7630-

0542

\section{Ailton Alves de Carvalho}

Universidade Federal Rural de

Pernambuco (UFRPE)

Recife - Pernambuco - Brasil

E-mail: ailtonalvesst@hotmail.com

Orcid: https://orcid.org/0000-0001-8783-

649X

\section{Hernande Pereira da Silva}

Universidade Federal Rural de

Pernambuco (UFRPE)

Recife - Pernambuco - Brasil

E-mail: hernandepereira@yahoo.com.br Orcid: http://orcid.org/0000-0002-20406994

\section{Soraya Giovanetti El-Deir}

Universidade Federal Rural de

Pernambuco (UFRPE)

Recife - Pernambuco - Brasil

E-mail: sorayageldeir@gmail.com

Orcid: http://orcid.org/0000-0002-7187-

7438
Renilson Pinto da Silva Ramos

Universidade Federal da Paraíba (UFPB)

João Pessoa - Paraíba - Brasil

E-mail: renilsonramos22@gmail.com

Orcid: https://orcid.org/0000-0003-3209-

514X

\section{Fernando da Silva Alexandre}

Universidade Federal de Pernambuco

(UFPE)

Recife - Pernambuco - Brasil

E-mail: fnando257@gmail.com

Orcid: https://orcid.org/0000-0003-0896-

9433

\section{Ana Célia Saraiva de Moura Garcia} Instituto Federal de Pernambuco (IFPE)

Recife - Pernambuco - Brasil

E-mail:anaclia1@gmail.com

Orcid: https://orcid.org/0000-0002-1542-

9876

\section{Adriana Karla Tavares Batista Nunes \\ Leal}

Instituto Federal de Pernambuco (IFPE)

Recife - Pernambuco - Brasil

E-mail: adrianakarlaleal@hotmail.com

Orcid: https://orcid.org/0000-0003-2485-

7108

\section{Valdilene Valdice de Santana}

Universidade Federal de Pernambuco (UFPE)

Recife - Pernambuco - Brasil

E-mail: valdilene-valdenice@hotmail.com Orcid: https://orcid.org/0000-0002-27423818 


\title{
Resumo
}

A atividade agropecuária é a principal setor usuário dos recursos hídricos no Brasil. No município de Ibimirim, Sertão de Pernambuco, Nordeste do Brasil, a agricultura irrigada foi impulsionada com a implantação de açude e sistema de irrigação pelo Departamento Nacional de Obras Contra as Secas, constituindo o Perímetro Irrigado do Moxotó. Este artigo tem por objetivo relatar o processo de gestão das águas para atividades agrícolas e identificar espaço-temporalmente alterações nas classes de uso e cobertura do solo, utilizando o NDWI e o NDVI. Para detalhamento descritivo e exploratório e pontual, foram realizadas observações diretas e registro fotográfico a partir de campanhas de campo. Foram analisados os dados de solo e precipitação pluviométrica, agregando imagens de cobertura vegetal e alocação de água do reservatório por meio de técnicas de sensoriamento remoto. Registros históricos do uso da água do açude demonstram que os solos próximos possuem elevado potencial para irrigação, porém devido à falta de manejo adequada do perímetro irrigado de lbimirim, registros de áreas salinizadas foram constatadas, principalmente em sistemas em que a irrigação é realizada pelo método de superfície. Além do mais, existe o uso exagerado da água do açude, que vem concentrando cada vez mais sal, como redução real do seu volume, principalmente nos anos de 1995, 2003 e 2019. Estes fatores são intensificados pela ausência de reformas no açude, falta de agregação de novas tecnologias, baixo nível de manutenção técnica dos equipamentos, diminuindo a eficiência operacional, assim como ausência de política de capacitação dos técnicos que realizam assistência aos produtores. Todos estes fatores necessitam de correção para que esta região possa adotar um modelo sustentável de produção.

Palavras-chave: Escassez; Demanda de água; Perímetro irrigado

\section{Water Management in Irrigation and Changes in Soil Coverage in an Artificial Reservoir in the Brazilian Semiarid}

\begin{abstract}
Agricultural activity is the principal user sector of water resources in Brazil. In the municipality of Ibimirim, Sertão of the Pernambuco, Northeast Brazil, irrigated agriculture was boosted with the dam and irrigation system implementation by the National Department of Works Against Droughts, constituting the Moxotó Irrigated Perimeter. This article aims to report the process of water management for agricultural activities and identify spatial and temporal changes in land use and land cover classes, using the NDWI and NDVI. For descriptive and exploratory and punctual detailing, direct observations and photographic records were carried out from field campaigns. Soil and rainfall data were analyzed, aggregating images of vegetation cover and reservoir water allocation through remote sensing techniques. Historical records of the use of water usage from the weir demonstrate that nearby soils have a high irrigation potential but due to the lack of proper management of the irrigated perimeter of Ibimirim, records of salinized areas were found, mainly in systems where irrigation is carried out by the method of surface. Furthermore, there is an exaggerated water use from the dam, which has been concentrating more and more salt, as an actual reduction in its volume, especially in 1995, 2003 and 2019. These factors are intensified by the lack of reforms in the dam, lack of aggregation of new technologies, low level of technical maintenance of equipment, reducing operational efficiency, plus the lack of training policy for technicians who assist producers. All these factors need correction so that this region can adopt a sustainable production model.
\end{abstract}

Keywords: Scarcity; Water Demand; Irrigated Perimeter. 


\section{Introdução}

A produção de alimentos é uma prioridade em muitos países, e a agropecuária, principal usuária dos recursos hídricos, deve não apenas fornecer alimentação para uma população crescente, mas também economizar a água visando a outros usos. O desafio é desenvolver e aplicar métodos racionais do uso, reuso e manejo da água na produção agropecuária em comunidades rurais, de forma a se obter maior produtividade com menor desperdício (EMBRAPA, 2018). Sendo a água essencial para a vida humana, e para os demais seres vivos, é necessário um uso consciente, já que a água potável está se tornando escassa no meio ambiente, em virtude do mau uso, do crescimento populacional e da ampla produção de alimentos (PESSOA et al., 2016), além disso, existe tendência de redução das chuvas para o semiárido brasileiro para os próximos anos (CARVALHO et al., 2020).

Para as secas nordestinas, apresentaram-se algumas soluções, como a irrigação feita através da construção de açudes e barragens e a destinação de verbas para socorros especiais (AZEVÊDO, 2015), tendo em vista que o uso de estratégias de convivência com a escassez hídrica no semiárido é voltado praticamente para a construção de açudes, poços com dessalinizadores e a construção de cisternas e, assim, possibilitando uma maior disponibilidade das águas (OLIVEIRA et al., 2017).

Dados como os provenientes de técnicas de sensoriamento remoto com uso de satélites da série LANDSAT têm sido, significativamente, usuais e prestativos no monitoramento para gerenciamento hábil dos recursos naturais, dentre eles os hídricos e dosséis vegetais em regiões áridas e semiáridas do globo. Uma das ferramentas que tem se apresentado ao estudo da problemática da seca é o Sensoriamento Remoto (SR). Esta tecnologia, dentre outros usos, detecta alterações na cobertura do solo e presença de água, proporcionando através de índices de vegetação, o diagnóstico e planejamento socioambiental. O SR constitui uma solução de baixo custo e abrangência de grandes áreas geográficas e registros temporais (BACALHAU et al., 2017, p. 284).

A partir do conhecimento das características físicas dos objetos de uma dada região e seu comportamento espectral (interação da radiação solar com os objetos que compõe o mosaico da superfície terrestre como os rios, a vegetação, o tipo de solo, a rocha, etc.) é possível fazer o monitoramento das condições ambientais da área em questão e descobrir suas possíveis modificações (AMORIM et al., 2007; RODRIGUES et al., 2017). No que tange aos recursos hídricos Finch (1997) relata que o monitoramento desses recursos pode dar aviso 
prévio de escassez de água iminente, permitindo ações para amenizar a situação a ser tomada em tempo bom. É possível identificar uma área inundada por um lago ou reservatório, com uso de imagens de satélites com sensores na banda do infravermelho próximo (entre 0,76 e 0,90 micrômetros), onde os corpos d'água absorvem a maior parte da radiação (COSTA, 2019).

Porém, em determinadas situações, usuários de açudes, a exemplo o açude do Poço da Cruz, necessitam de compartilhamento de sua água para as diversas atividades agropecuárias, dessedentação de animais e abastecimento público, possíveis somente através de um bom gerenciamento do recurso hídrico aliado a informes acerca das alterações do uso e cobertura do solo pelo meio de índices de vegetação semiautomatizados. $O$ açude conhecido popularmente como Poço da Cruz (Açude Público Federal Engenheiro Francisco Saboia) está situado no município de Ibimirim - Pernambuco, sendo um dos reservatórios construídos através da implementação de programas sociais estatais que viabilizaram estratégias para a melhoria da qualidade de vida do homem sertanejo por meio da irrigação, é considerado atualmente o maior espelho d'água do estado.

De acordo com Silva (2006) a agricultura irrigada no município de Ibimirim foi impulsionada com a implantação pelo Departamento Nacional de Obras Contra as Secas (DNOCS) do Perímetro Irrigado do Moxotó. Este teve seu início em 1930, com a obra do açude Engenheiro Francisco Saboia (Poço da Cruz), sendo inaugurado em 1958 na gestão Federal de Juscelino Kubitscheck (SILVA, 2006). Essa área irrigada é uma fonte de renda muito importante para a região e para Pernambuco, sendo de fundamental importância a conservação e criação de ações integradas às geotecnologias para o acompanhamento do uso consciente do rio e sua mata ciliar (LIMA et al., 2019, p. 300).

Tendo em vista a escassez hídrica da região, demanda de água para o consumo humano e atividades agropastoris, objetivou-se com este estudo relatar o processo de gestão das águas para atividades agrícolas e identificar espaço-temporalmente alterações nas classes de uso e cobertura do solo utilizando para tal índices de vegetação NDWI e NDVI obtidos com imagens TM e ETM+ de satélites Landsat 5, 7 e 8 e dados a acerca do uso e cobertura da terra coletados do projeto mapbiomas, ao longo do reservatório Poço da Cruz, em Pernambuco, Brasil. 


\section{Material e Métodos}

\section{1 Área de estudo}

O estudo foi conduzido no Município de Ibimirim, estado de Pernambuco, a 334 km da capital Recife, na Microrregião do Sertão do Moxotó, Submédio do Vale do São Francisco, região Semiárida do Nordeste do Brasil, prioritariamente no Açude Público Federal Engenheiro Francisco Saboia (Poço da Cruz) e Perímetro Irrigado do Moxotó (Pimox) (Figura 1), respectivamente.

Figura 1: Localização geográfica do Açude Poço da Cruz e Pimox, Ibimirim - PE



Fonte: Elaborado pelos autores.

Essa localidade apresenta clima do tipo semiárido quente, ou BSw'h', segundo Köppen, com temperatura média anual de $25^{\circ} \mathrm{C}$. Os meses mais quentes, com registros máximos de temperatura entre $35^{\circ} \mathrm{C}$ e $40^{\circ} \mathrm{C}$, são novembro e dezembro, enquanto que as mínimas (aproximadamente $23^{\circ} \mathrm{C}$ ) ocorrem em julho e agosto (SILVA, 2006), sendo considerada, portanto, uma das regiões mais vulneráveis à variabilidade climática atual e às 
mudanças climáticas futuras no país em virtude dos processos de desertificação (OBERMAIER, 2011; TAVARES; ARRUDA; SILVA, 2019).

Os solos predominantes na região de estudo são do tipo profundo, com caráter distrófico e acidez elevada predominante, representados pelos Neossolos Quartzarênicos; solos pouco profundos a profundos, com presença de textura arenosa ou média, drenados, representado pelo Neossolos Regolítico; e solos minerais, imperfeitamente drenados e mal drenados com teores elevados e sódio no subsolo, representados pelos Planossolos Nátricos. Outros tipos de solos também ocorrem: Latossolos Amarelos, Luvissolos, Podzólicos Amarelos, Neossolos Flúvicos, Vertissolos e Cambissolos (SILVA, 2006; TAVARES FILHO, 2010, p. 18). As principais culturas produzidas nas áreas especificamente irrigadas são o milho e a banana, que representam os principais produtos agrícolas comercializados no município (SALIN, 2010, p. 53), complementando-se de um pequeno percentual de outras culturas como o tomate, goiaba, coco, e outros predominantemente cultivados para fins de renda e subsistência.

\subsection{Coleta de dados e pré-processamento}

O período experimental para o desenvolvimento da pesquisa compreendeu os meses de outubro de 2016 a dezembro de 2018, apreciada por investigações minuciosas nos anos 2019 e 2020. Para a realização do estudo, inicialmente, foram efetivadas cuidadosas consultas a literatura com ênfase nos seguintes tópicos: 1. Manejo e gestão dos recursos hídricos do Açude Engenheiro Francisco Saboia (Poço da Cruz); 2. Gestão de água na irrigação; 3. Historicidade do açude Poço da Cruz. Adiante foram realizadas campanhas de campo para observações diretas e registro fotográfico da área de estudo (averiguação do tipo de sistema de irrigação utilizado, condições do solo e equipamentos estruturais, vazão do açude, culturas produzidas, etc.).

Dados de solos foram coletados junto a Empresa Brasileira de Pesquisa Agropecuária (Embrapa) diretamente no Mapa de Reconhecimento de Baixa e Média Intensidade de Solos do Estado de Pernambuco - Plataforma ZAPE. Além disso, também foram coletados dados pluviométricos anuais de 9 estações meteorológicas, a saber: Arcoverde (CHESF), Arcoverde (INMET, 2018), Custódia, Custódia (CHESF), Ibimirim (IPA), Ibimirim (Poço de Cruz), Inajá, Inajá (CHESF), Sertânia (Algodões), Sertânia (Cadoca) e feito o processo de interpolação pelo método Ponderação pelo Inverso da Distância (Inverse Distance Weighting), um método de interpolação para pontos espalhados espacialmente. Essa técnica determina os valores dos 
pontos usando uma combinação linear ponderada dos pontos amostrados, o peso de cada ponto é o inverso de uma função da distância (MARCUZZO; ANDRADE; MELO, 2011).

Para fins de identificação de possíveis adulterações nas classes de uso e cobertura do solo relativos à gestão de água na irrigação do Açude Poço da Cruz foi realizada uma análise espaço-temporal da área de estudo aproveitando cenas baixadas espontaneamente da coleção 5 do Mapbiomas Brasil, a qual foi lançada recentemente e mapeou todo o Brasil de 1989 a 2019 (MAPBIOMAS, 2021). Os dados coletados foram especificamente escolhidos nos mesmos anos das imagens dos satélites Landsat 5 e 8, para uma melhor comparação.

Para demonstrar os recursos hídricos e sua frequência em determinados pontos dentro da área de estudo foram baixadas imagens provenientes de sensores de diferentes satélites da série Landsat diretamente do Global Surface Water Project - site: https://globalsurface-water.appspot.com/, uma máquina do tempo virtual que mapeia a localização e distribuição temporal das superfícies de água a escala global nas últimas 3,6 décadas (GLOBAL SURFACE WATER PROJECT, s.d).

Desse modo, o intervalo de análise foi de 26 anos levando em consideração imagens datadas com passagens nos anos 1995/09/30, 2003/10/12 e 2019/10/24 do período seco (verão) na órbita 216, ponto 65, com resolução espacial de 30 metros. Foram utilizadas cenas de três diferentes sensores para realizar a análise/averiguação dos índices espectrais, os sensores TM (Themactic Mapper), a bordo do satélite Landsat-5 que tem sete bandas, das quais somente a banda 6 possui resolução espacial para $120 \mathrm{~m}$ e as demais para $30 \mathrm{~m}$, e ainda o sensor Enhanced Thematic Mapper Plus (ETM+) do Landsat 8 que possui a bordo dois sensores, o Operacional Terra Imager (OLI) e Termal Infra Red Sensor (TIRS).

Para visualizar os alvos, foram selecionadas sequencialmente as bandas 5, 4 e 3 da imagem do sensor TM e as bandas 6, 5 e 4 do sensor OLI, correspondentes às faixas do infravermelho médio infravermelho próximo e vermelho visível, a partir das quais gerou-se uma composição colorida para cada ano selecionado, nas cores vermelho $(R)$, verde $(G)$ e azul (B) (PERUZZO et al., 2019, p. 29).

\subsection{Mapa de localização da área investigada}

Para confecção do mapa da área do estudo em comento, a primeira etapa consistiu em realizar um recorte da área pertencente ao município de lbimirim delimitando o Perímetro Irrigado do Moxotó (PIMOX) que se encontra logo a sua jusante, a partir de vetorização de 
uma shape proveniente de mapas e plantas de posição e direção das vias terrestres (malhas viárias) que foram adquiridos junto à sede do Departamento Nacional de Obras Contra as Secas (DNOCS) pelo qual foi possível visualizar que este se acha em plena área da coluna d'água do Açude Poço da Cruz.

Todos os outros dados vetoriais foram adquiridos do Instituto Brasileiro de Geografia e Estatística (IBGE). Para esta etapa utilizou-se o software ArcGIS 10. 5. A partir da reprojeção e pós-obtenção dos dados raster com a composição de cores RGB real foi produzido um mapa de localização da área de estudo.

\section{Processamento de dados}

No uso e cobertura da terra, os dados obtidos foram reclassificados no software ArcGIS 10.5, utilizando como a base a tabela de sugestão de classificação disponibilizada pelo próprio Projeto Mapbiomas. As áreas em $\mathrm{Km}^{2}$ foram medidas e os mapas confeccionados com as cores sugeridas pela própria tabela.

Para aquisição do índice de Umidade - NDWI foi utilizada a metodologia adotada por Pereira et al. (2016). Este autor relata que com o uso do índice NDWI (Normalised Difference Water Index), é possível delimitar os corpos hídricos, em virtude da baixa reflectância da água no verde (0,52 a 0,60 micrômetros) e no infravermelho próximo em contraste com outras superfícies, tipo de vegetação e solo. Desse modo, foi usada a seguinte fórmula desenvolvida por Gao (1996):

\footnotetext{
NDWI $=$ GREEN-NIRGREEN +NIR

Onde,

NDWI, o índice de água por diferença normalizada;

GREEN, a banda espectral do verde.

NIR, a banda espectral do Infravermelho Próximo
}

A determinação do Índice de Vegetação por Diferença Normalizada (NDVI) foi calculado a razão entre a diferença das refletividades das bandas do infravermelho próximo (banda 4 - 0,64 $\mu \mathrm{m}$ a 0,67 $\mu \mathrm{m}$ ) e do vermelho (banda $5-0,85 \mu \mathrm{m}$ a 0,88 $\mu \mathrm{m}$ ), e pela soma delas: 
Onde,

NDVI, o Índice de Vegetação por Diferença Normalizada;

NIR, a banda espectral do Infravermelho Próximo;

$\mathrm{R}$, a banda espectral do Vermelho

Para o NDVI, que o resultado tem uma variância que existe entre os valos -1 e +1 , a resposta espectral com resultado abaixo de 0 representa exclusivamente os corpos hídricos, pelo alto nível de absortância que a água possui em relação ao espectro eletromagnético. Regiões de solo exposto apresentam valores de resposta espectral que varia entre 0,1 e 0,2. No que diz respeito aos valores de 0,2 e 0,4 existe a representação de uma quantia diminuta de vegetação. Os valores do intervalo que está entre 0,4 e 0,6 representa uma vegetação mais arbustiva e acima de 0,6 é a resposta que corresponde a uma vegetação mais densa. Todas as definições a respeito das classes definidas e das classificações por intermédio dos valores a resposta espectral foram definidas através dos números abordados nos trabalhos de Suliman et al. (2015); Meroni et al. (2017), Batista (2018) e Shiferaw et al. (2019), nos quais todas as equações realizadas referentes foram efetuadas em ambientes computacional, num Sistema de Informações Geográficas (SIG).

Antecedendo ao cálculo do NDVI e NDWI, as imagens foram submetidas à calibração da radiância e reflectância através do cálculo da radiância das bandas necessárias para o trabalho. Cálculo este que consiste na conversão dos números digitais de cada pixel das imagens em grandezas de radiância espectral no topo da atmosfera como demonstrado por Santos et al (2016), seguindo a equação:

Onde,

$L \lambda$, a radiância espectral no topo da atmosfera;

$\mathrm{ML}$, o fator multiplicativo reescalonado da radiância para a banda específica;

Qcal, o número digital do pixel;

$\mathrm{AL}$, o fator aditivo reescalonado da radiância para a banda específica 
Os parâmetros das imagens para cada dia analisado foram obtidos nos metadados de cada imagem, advindo juntamente à imagem (BATISTA, 2018). Para correção da reflectância planetária no topo da atmosfera, as imagens foram submetidas a seguinte equação:

(3)

Onde,

$\rho \lambda^{\prime}$, a reflectância planetária no topo da atmosfera sem correção do ângulo solar;

Mp, o fator multiplicativo reescalonado da reflectância para a banda específica;

$L \lambda$, a radiância espectral;

A $\rho$, o fator aditivo reescalonado da reflectância para a banda específica

Para correção da reflectância planetária no topo da atmosfera das imagens do LANDSAT 8 com resolução temporal de aproximadamente 16 dias e com resolução espacial de 30 m, e necessário a correção de acordo com a inclinação solar, utilizando a seguinte fórmula (USGS, 2016):

Onde,

$\rho \lambda^{\prime}$, a reflectância planetária no topo da atmosfera sem correção do ângulo solar;

$\rho \lambda$, a reflectância planetária no topo da atmosfera corrigida de acordo com a inclinação solar;

ӨSE, o ângulo de inclinação do sol do centro da cena em graus

Após as correções das imagens, foram elaboradas as imagens de NDVI e NDWI utilizando-se da ferramenta da calculadora Raster, na qual a diferença entre as bandas de cada uma das equações foi realizada e que obteve em seu resultado uma variação entre -1 e +1 (quanto mais próximo de +1 , indica a maior densidade do verdor possível de cobertura vegetal para o NDVI e uma maior quantia de concentração de umidade no caso do NDWI) (BALLÉN; SOUZA; LIMA, 2016). Todo o processamento digital das imagens foi realizado através do software da empresa ESRI ArcGIS 10.5. 


\section{Resultados e Discussão}

4.1 Pedologia do Perímetro Irrigado do Moxotó (PIMOX) - Fragilidades e possibilidades

Como advertem Knüppe e Meissner (2016), para a gestão sustentável dos recursos hídricos, se faz mister estudos focados na tipologia dos solos e o uso destes nas diversas atividades antrópicas. O índice percentual de uso do horário reservado para a irrigação pode variar muito em função do solo. Por exemplo, um solo arenoso não retém muita água, o que leva a irrigar menor quantidade tornando necessária maior frequência de irrigação, não sendo possível utilizar somente o horário reservado (geralmente das $21 \mathrm{~h} 30$ às 06h00) para as atividades de irrigação e aquicultura (SENAR, 2019, p. 63).

Levando-se em consideração os solos da região (Figura 2), verifica-se a susceptibilidade do perímetro irrigado aos riscos de salinização desses, uma vez que o método de irrigação adotado, na maioria dos casos por superfície, no sistema por sulcos, favorece o processo de salinização, principalmente no tipo de solo em que é praticado (predominância de Neossolos flúvicos no perímetro irrigado). Segundo Valladares; Faria (2004) este problema tem sido provocado tanto pelo tipo de sistema de irrigação, muitas vezes inadequado às características do solo, quanto pela maneira como a atividade é executada, fazendo mais uma "molhação" do que irrigando.Figura 2: Mapa de solos com potencial de irrigação do Município de Ibimirim - PE. 
Fiqura 2: Mapa de solos com potencial de irriqação do Município de Ibimirim - PE.

A

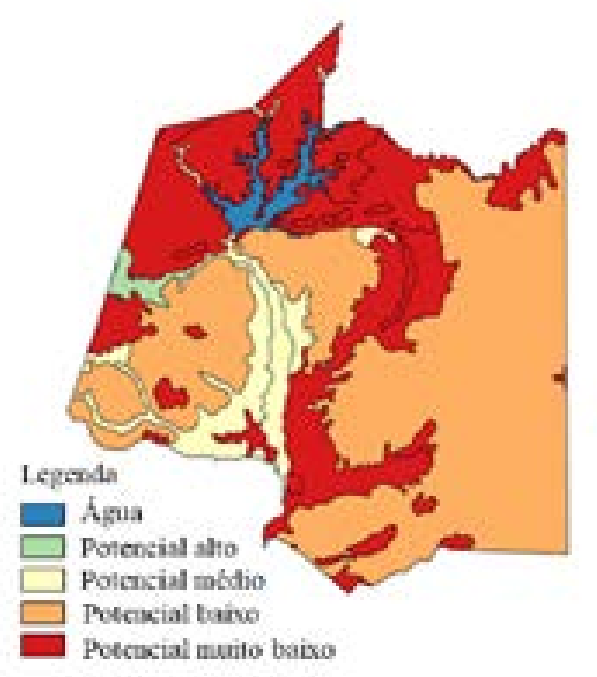

B

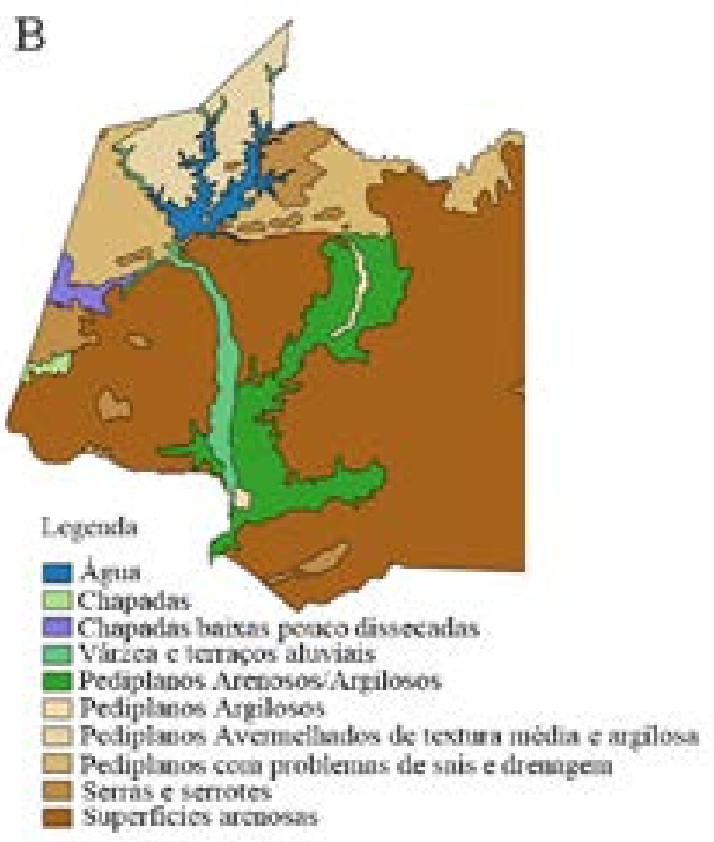

Fonte: Adaptado de Embrapa - ZAPE (2002).

Coelho et al. (2005) apontam que a irrigação por sulcos com uso de pulso ou "surge flow" pode reduzir significativamente as perdas por percolação, enquanto outros autores (DUQUE, 1980; OLIVEIRA, 2015) argumentam que dados baseados no consumo de água de culturas irrigadas pelo sistema de sulcos e inundação, nos açudes públicos, indicam que são necessários $70.000 \mathrm{~m} 3$ de água dentro da represa para garantir a irrigação de um hectare durante um ano, estando incluídas as perdas por evaporação, infiltração e a aplicação na cultura.

O problema de salinização e/ou alcalinização é mais frequente em regiões tropicais de clima quente e seco, caracterizado por elevadas taxas de evapotranspiração e baixos índices pluviométricos, a exemplo do semiárido do nordeste brasileiro, onde no contexto regional, se concentram atualmente as terras mais intensamente cultivadas. Com o uso da irrigação, esse risco ainda é maior (TAVARES FILHO, 2010).

A Figura 2 apresenta os solos com potencial alto, médio e baixo para a agricultura irrigada situados a jusante do Açude Poço da Cruz, no qual percebe-se existência de poucos terrenos com potencial alto para tal atividade. Já na imagem (B) é possível perceber solos 
de chapadas e superfícies arenosas em maior parte do território do município de Ibimirim, localizados também a jusante do açude. Tavares Filho (2010) relata que o projeto de irrigação realizado no município de Ibimirim não levou em consideração as condições de solo e do clima da região. Por se tratar de uma região semiárida, onde a evaporação é acentuada, o tipo de irrigação utilizado - de inundação - foi um dos fatores que levou a degradação do solo através da concentração de sais. Estudos realizados por Freire et al. (2014) também evidenciaram, na Microrregião do Sertão do Moxotó, que estes solos apresentam problemas de degradação pelo acúmulo de sais, principalmente por sais de sódio (sodificação).

Como exemplo disso, pode-se destacar o desperdício que alguns irrigantes praticam deixando o sistema funcionando por mais tempo que o necessário sem turno de rega pré-estabelecido, como se pode destacar em visitas realizadas nos lotes, nos quais se pode observar o afloramento de sais na superfície do solo (Figura 3). Salin (2010) constatou que, nesta mesma área de estudo, a atividade irrigada tem contribuído para os processos de degradação do solo e dos recursos hídricos, além de apresentar limitada autonomia produtiva dos agricultores devido à dependência de insumos externos.

Figura 3: Afloramento de sais em solo de área irrigada em lotes do perímetro irrigado do Moxotó, em Ibimirim - PE, em 2016
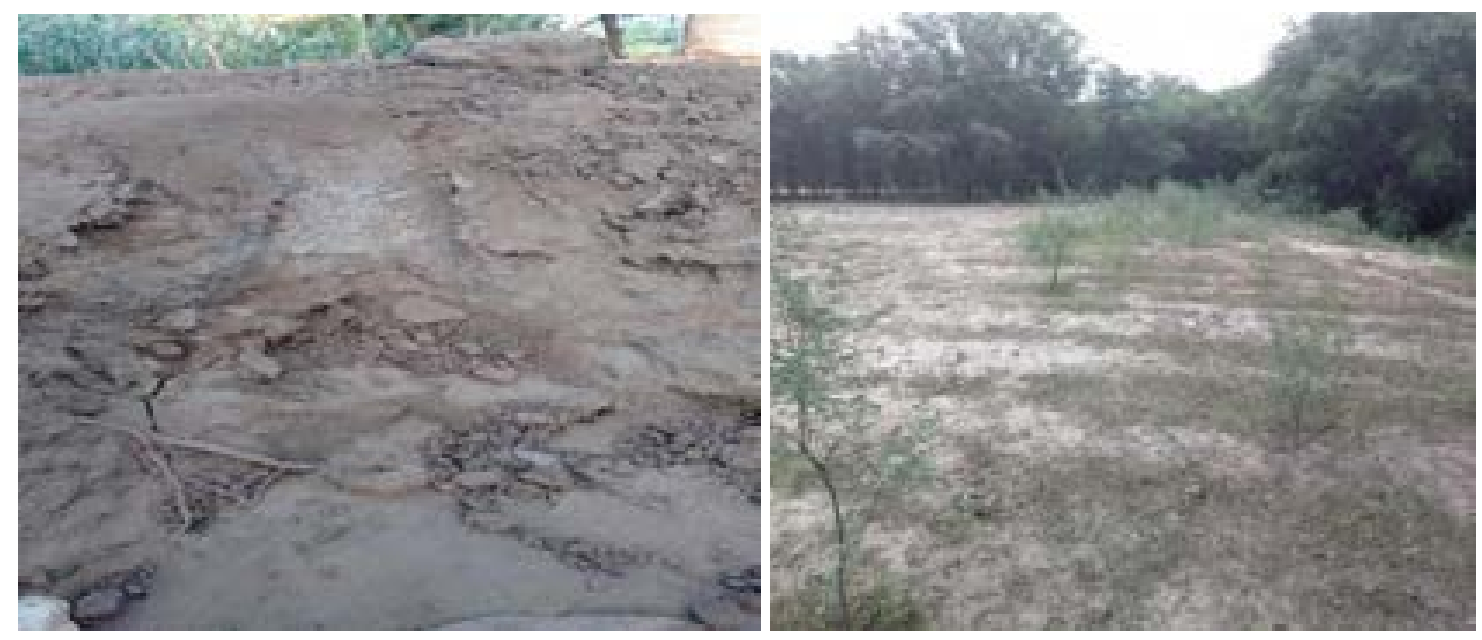

B

Fonte: Acervo dos autores (2016\2019).

De acordo com Garcia et al. (2019), em estudo na Bacia do Rio Moxotó, nas áreas salinizadas com processo de salinização há grande predominância de espécies exóticas densas da espécie de Prosopis juliflora (S.W) D.C (algaroba), presente nos domínios dos 
Neossolos Flúvicos, conforme podemos observar com detalhamento na Figura 3 A e B. Mora, Herrero e Weindorf (2017) observaram que a distribuição espacial dos íons e as mudanças temporais em profundidades de solo salinizados é comparável a relação aos fatores ambientais e de manejo destes, sendo imperativo que formas de proteção destes recursos naturais sejam observadas. Algumas técnicas foram testadas no intuito de avaliar as implicações da salinidade nos solos em virtude do mau uso da água na irrigação, dentre as quais se destaca o estudo desenvolvido na planície de Bohai Lowland, no norte da China, por meio da realização de experimento no qual se utilizou cobertura morta na produção de trigo de inverno em solos salinos de terras secas (ZHANG et al., 2018).

Para o estudo anteriormente destacado foram avaliados os efeitos da cobertura de filme plástico do subsolo na umidade do solo, salinidade do solo e eficiência no uso da água do trigo de inverno (ZHANG et al., 2018), a aplicação de corretivos tendo rebatimento na comunidade microbiológica (LUO et al., 2018), adoção de planos de manejo envolvendo as comunidades (HUANG et al., 2019), uso de tecnologias de sensoriamento remoto (ASFAW; SURYABHAGAVAN; ARGAW, 2018), dentre outras estratégias. Para Hu et al. (2018), os efeitos da matéria orgânica na estrutura do solo ácido são positivos, podendo auxiliar na correção destes. O uso de agrossistemas é ressaltado por Sánches-Moreno et al. (2018), em estudo de áreas semiáridas do Mediterrâneo, demonstrando como o manejo orgânico eleva o que denominou de "saúde do solo", corrigindo a salinidade e acidez.

4.2 Índices de precipitação pluviométrica e gestão das águas do Açude Poço da Cruz

Considerando o índice de aridez (la), calculado pela relação entre a precipitação (454 mm) e a evapotranspiração potencial [evaporação (2300 mm + transpiração)] (Equação 3), tem-se que este, observando que no denominador está apenas o valor de evaporação, é classificado como árido $(0,19)$ (Tabela 1$)$, o qual poderia diminuir ainda mais esse índice com os dados de transpiração.

$\mathrm{la}=\mathrm{P} / \mathrm{ETP}$

Eq.

Onde:

la - índice de aridez, adimensional;

P - Precipitação média anual, mm; e

ETP - Evapotranspiração Potencial anual, mm. 
Tabela 1: Classificação da classe climática para o índice de aridez (ia), região central do semiárido brasileiro, período 1961 a 2015

\begin{tabular}{|l|l|}
\hline Classe climática & la \\
\hline Árido & $<0,20$ \\
\hline Semiárido & $0,21-0,50$ \\
\hline Sub-úmido seco & $0,51-0,65$ \\
\hline Sub-úmido e úmido & $>0,65$ \\
\hline
\end{tabular}

Fonte: Lopes et al. (2017).

Dados relativos à precipitação pluviométrica na região do Sertão Pernambucano evidenciam as quantidades de chuvas irregulares, como é possível observar com dados apresentados na Figura 4.

Figura 4: Espacialização pluviométrica anual do Pimox nos anos de 1995, 2003 e 2019

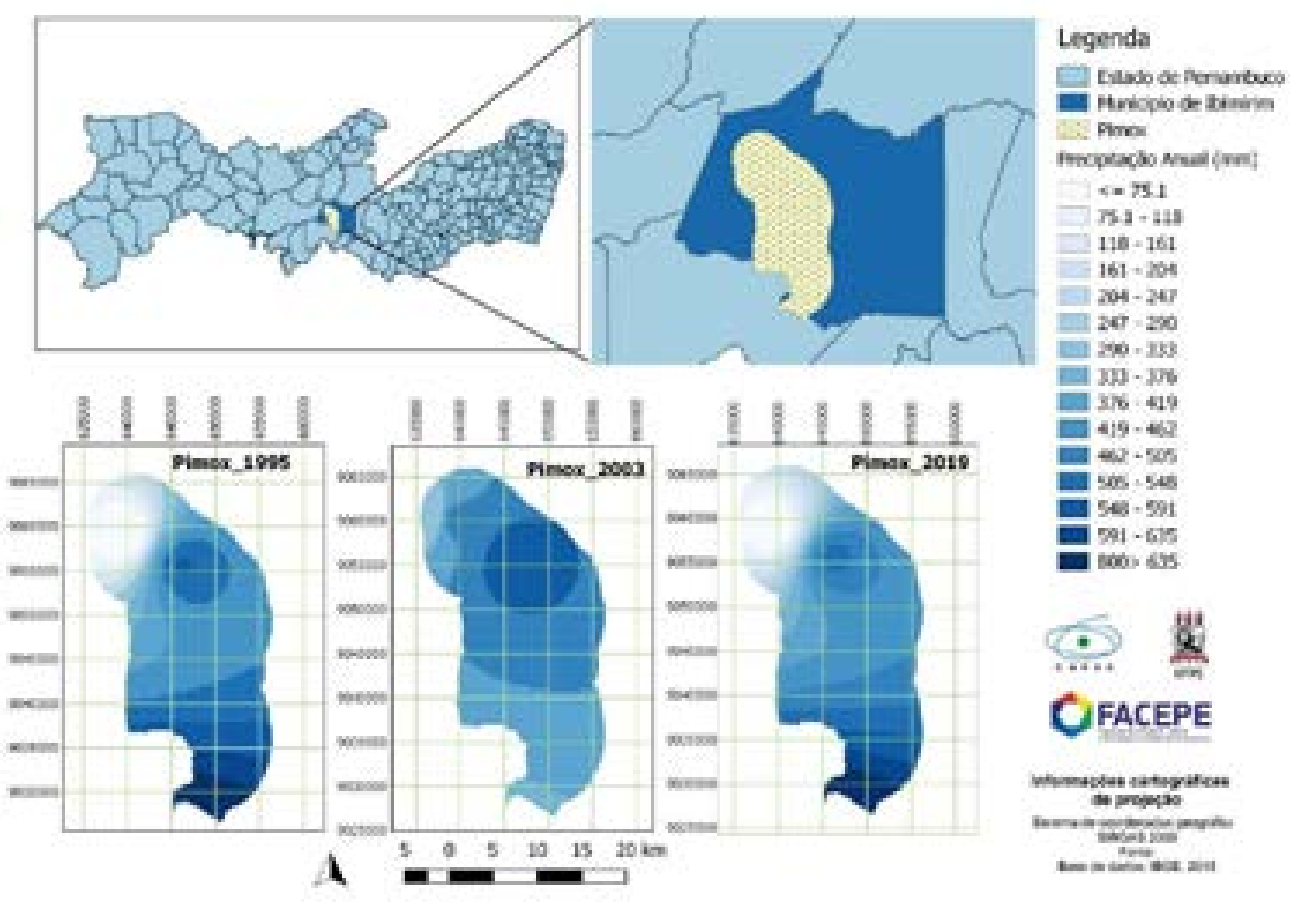

Fonte: Elaborado pelos autores.

Observa-se a distribuição das precipitações irregulares na região do Pimox, sendo os anos de muito baixa precipitação o ano de 1995 e 2019. O impacto da baixa escassez da precipitação para o ano de 2019 pode-se ser evidenciado no Quadro 1, que mostra o colapso do açude Poço de Cruz. Também se evidencia a diminuição do volume d'água entre os anos de 2012 e 2019, que correspondem aos anos de cheia e secas com maior volume 
d'água em metros cúbicos (m3) e média anual registrada para o ano de 2012, porém seguido de reduções significativas em virtude das sucessivas secas prolongadas no Município de Ibimirim.

Quadro 1: Comparação da evolução do volume do açude Poço da Cruz ao longo dos anos

\begin{tabular}{|l|l|l|}
\hline Ano & Volume $\left(\mathrm{m}^{3}\right)$ & Volume médio anual (\%) \\
\hline Cap. Máxima & $504.000 .000,00$ & 100 \\
\hline 2012 & $189.689 .126,25$ & 37,6 \\
\hline 2013 & $96.865 .775,00$ & 19,2 \\
\hline 2014 & $54.162 .890,00$ & 10,7 \\
\hline 2015 & $30.204 .000,00$ & 6,00 \\
\hline 2016 & $22.755 .000,00$ & 4,50 \\
\hline 2017 & $10.531 .886,40$ & 2,09 \\
\hline 2018 & $46.542 .416,60$ & 9,23 \\
\hline 2019 & $37.215 .423,93$ & 7,38 \\
\hline
\end{tabular}

Fonte: Aguiar (2019).

Ressalta-se, que a área do espelho d'água no ano de 2004 era estimada em mais de 5063ha, já em 2016, o espelho d'água era estimado 338ha. Diante de elevados índices de evapotranspiração anual, o açude Poço da Cruz necessita de atenção específica com relação ao manejo das águas, pois o volume atual está abaixo dos 30.000.000m3, o que corresponde a menos de $6,0 \%$ da capacidade de armazenamento, que é da ordem de $504.000 .000 \mathrm{~m} 3$ (APAC, 2016). No período de cheia (2004), muitos moradores e agricultores residentes ao longo da região ribeirinha do Rio Moxotó tiveram que abandonar temporariamente suas residências, lotes, casas campestres no intuito de manterem salvas suas vidas e de seus animais (Figura 5). 


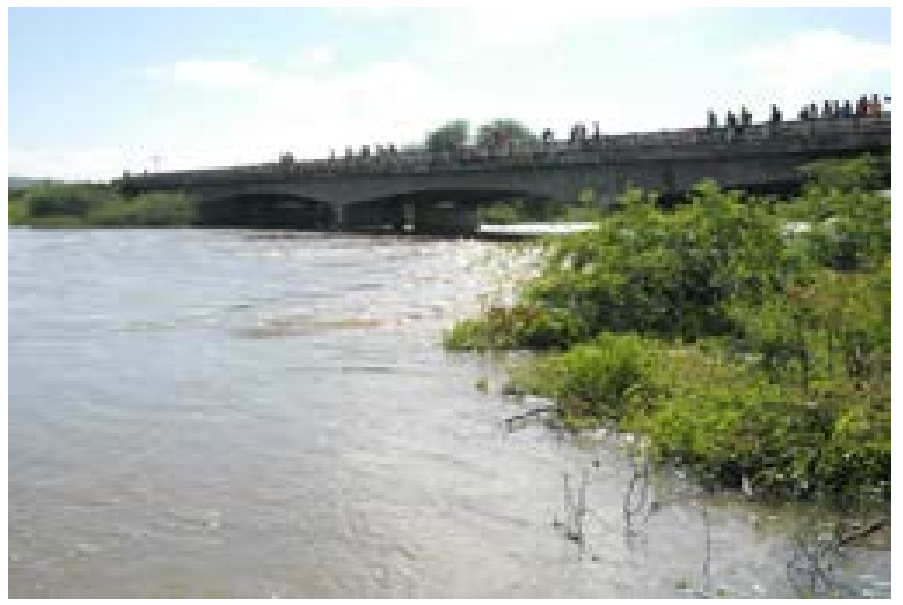

A

Fonte: Acervo dos autores.

Atributos impactuosos inquietantes, averiguados em campo, que é imprescindível destacar, são as poucas reformas, acompanhamentos e manutenção técnica dos equipamentos que compõem as obras de engenharia do Açude Poço da Cruz. Falta aperfeiçoamento e capacitação dos envolvidos nessas atividades. Dentre esses atributos, pode-se citar a carência de limpeza dos sangradouros, margens e leitos do açude e canais de irrigação do PIMOX sendo invadidos e deteriorados pela planta invasora algarobeira (Prosopis juliflora) (Sw.) DC., demonstrado na (Figura 6), disposição de resíduos sólidos e esgoto doméstico in natura em locais ou vilas onde o canal basal e seus ramais percorrem sem o devido tratamento prévio. Além disso, na maioria das vezes falta mantimento de comportas com a finalidade de evitar desregulação no nível de vazão do reservatório e possíveis danos como enchentes.

Figura 6: Invasão de algarobeiras às margens do canal principal do Pimox, 2020.

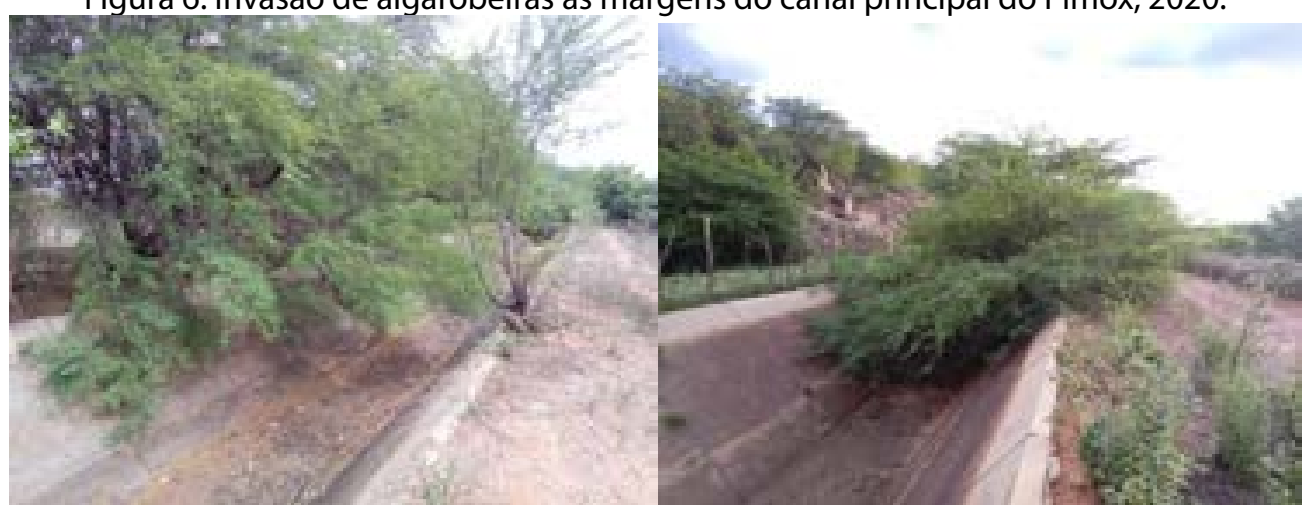




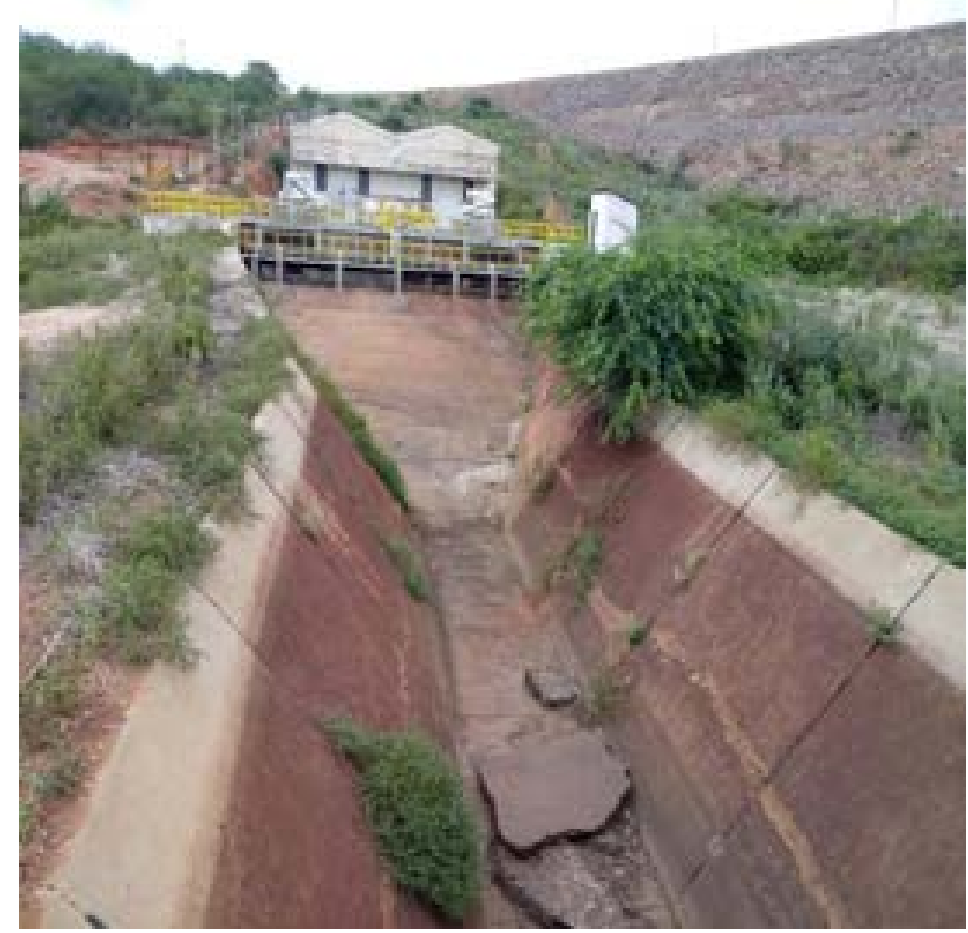

Fonte: Acervo dos autores (2020).

B

A bacia do Rio Moxotó em termos hidrológicos é pobremente monitorada, principalmente na região a montante ao reservatório, e a exploração das águas do açude realizada de forma pouco eficiente (MELO, 2011, p. 36). Aguiar (2019) aplicando a metodologia de Gestão integrada da água e do solo nas margens do reservatório Poço da Cruz em Ibimirim, Pernambuco, verificou que alguns atores que deviam se fazer mais presentes são o Instituto Brasileiro do Meio Ambiente e dos Recursos Naturais Renováveis (IBAMA) e a Agência Estadual do Meio Ambiente (CPRH), fiscalizando e monitorando a área, para assim garantir o desenvolvimento sustentável da região sem degradação ao meio ambiente. Mas foi constado que há poucos profissionais disponíveis, e os poucos que existem, ficam na capital, no Recife (AGUIAR, 2019, p. 58).

\section{3 Índice de Água por Diferença Normalizada (NDWI)}

Através das imagens de NDWI evidenciou-se que o índice de umidade relaciona a quantidade de água por unidade de área na vegetação (GAO, 1996; LIMA et al., 2019), afirmando aquilo também acatado por Abreu et al. (2020), os quais relatam a função principal desta técnica (NDWI) é justamente realçar os corpos hídricos presentes na imagem, para uma 
melhor visualização. O NDWI utiliza radiação refletida no infravermelho próximo e luz verde visível para a identificação da água e sua distinção em relação ao solo e à vegetação terrestre representando um método desenvolvido para delinear corpos d'água em superfície a partir de imagens digitais obtidas por sensoriamento remoto (CUNHA et al, 2020). Mediante o exposto, os resultados do índice NDWI para as datas de 30 de setembro de 1995, 12 de outubro de 2003 e 24 de setembro de 2019 do período seco, foram analisados na Figura 7. Percebeu-se que os valores máximo e mínimo com relação ao NDWI para o satélite Landsat-5 e Landsat-8 foram de -0,50 e 1,0;0,72-1,00; -0,55-1,00 respectivamente.

Figura 7: Espacialização do NDWI no município de Ibimirim nos anos de 1995, 2003 e 2016.
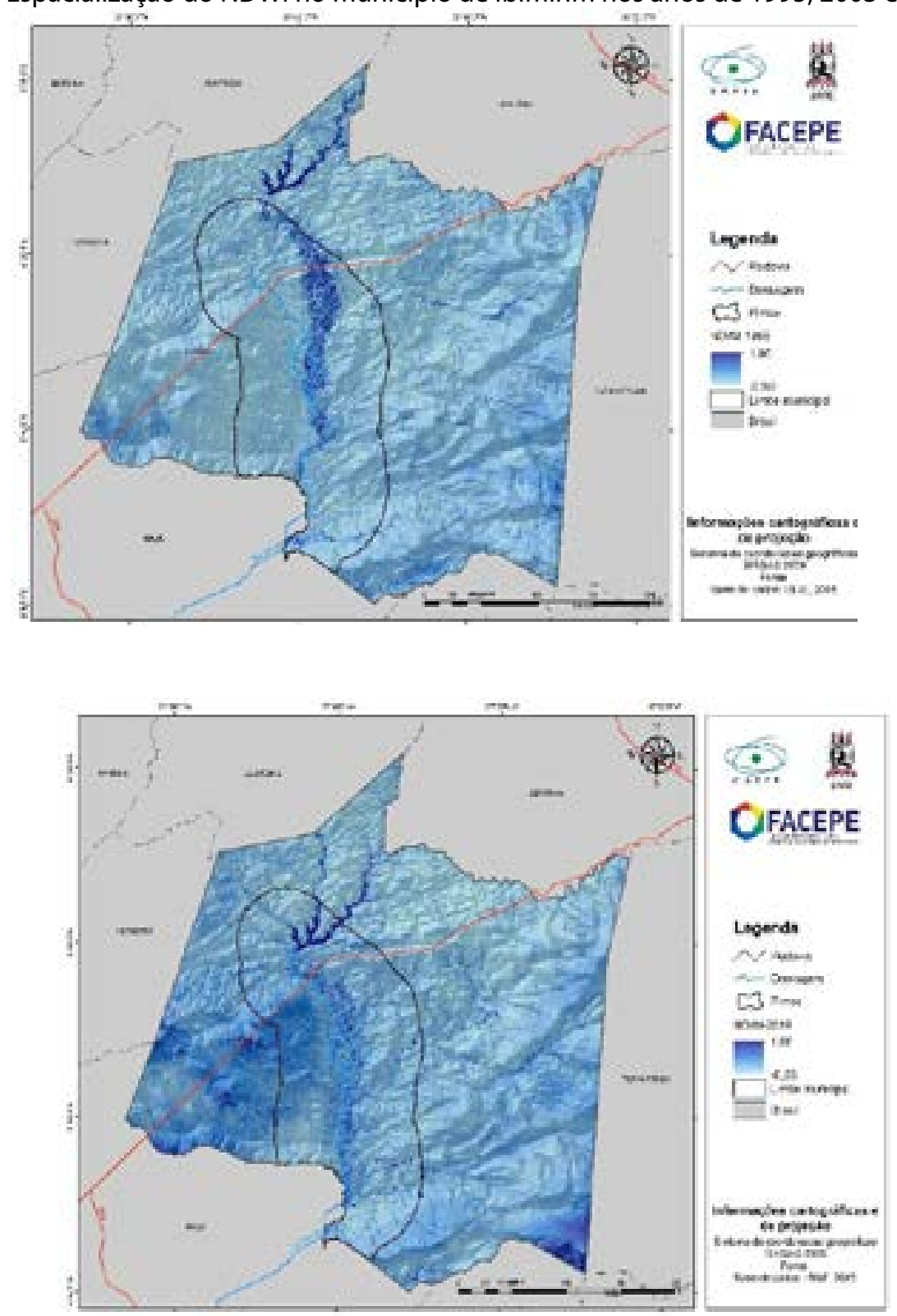

Fonte: Elaborado pelos autores. 
Evidencia-se para o ano de 1995, diminuição escalar em coluna d'água, conforme se pode observar no NDWI referente a essa data que é o primeiro ano de análise. Um quantitativo significativo de campos úmidos foi encontrado espacializado principalmente na área onde se localiza o reservatório Poço da Cruz, em Ibimirim e nas proximidades do rio Moxotó com valores que se aproximam do valor +1 , no qual se encontra sem dúvidas corpos hídricos. Quando se discute acerca de valores relevantes, o ano de 2003 se destaca perante os outros, pois foi marcado por uma intensa estiagem, antecedendo as fortes chuvas do ano 2004. Destaca-se também o mau gerenciamento dos recursos hídricos, que eram utilizados para a atividade agrícola (irrigação) a jusante do açude Poço da Cruz, sobretudo ao longo dos terrenos do Perímetro Irrigado do Moxotó (Pimox).

Ao analisar o ano de 2019, é possível observar que o reservatório contava com $7,38 \%$ de sua capacidade total de acúmulo de água, um volume é menor se comparado aos anos que o precederam, dessa forma é configurado um menor regime pluviométrico no ano discutido. Entretanto se levado em comparação com as outras datas estudadas em 2019 ainda havia uma quantia semelhante à área afetada pelo regime de chuvas. Espacialmente é possível verificar um menor espalhamento em tamanho de área ao se tratar de valores altos, na representação dos corpos d'água tanto ao longo do rio Moxotó quanto especificamente no açude de Ibimirim.

Ao observar os mapas é possível realizar uma análise com o viés de comparação, no que pode obter-se uma visão específica a respeito das alterações na espacialização da distribuição dos recursos hídricos dentro do município de Ibimirim. Em conjunto com os dados pluviométricos, o NDWI ajuda na verificação da evolução da dinâmica que rege o funcionamento corpos hídricos em todo município e na avaliação do objetivo da pesquisa que é o reservatório, uma vez que esse corpo hídrico realiza o manejo das águas para o munícipio.

\section{4 Índice de Vegetação por Diferença Normatizada (NDVI)}

Para PERUZZO et al. (2019) baixos valores de NDVI configuram vegetação estressada ou área degradada por presença de ação antrópica, decorrente de escassez hídrica, que tem como consequência a exposição do solo. Em relação a aplicabilidade do NDVI voltado para análises de conservação e degradação de cobertura vegetal dos ambientes áridos, onde predominam açudes como o Poço da Cruz, em Ibimirim - PE, Albuquerque et al. (2019) e Bacalhau et al. (2017) apontam que uma das causas para o declínio do NDVI é a 
falta de chuvas, visto que a água é um elemento fundamental para a saúde da vegetação (considerando as especificidades das espécies), que por sua vez dependem da localização e do clima da região.

A modelagem dos índices de vegetação como o NDVI baseia-se no comportamento oposto da refletância da vegetação na região do visível, ou seja, quanto maior a densidade vegetal, menor é a refletância em função da absorção da radiação pelos pigmentos fotossintetizantes e quanto maior a densidade vegetal, maior a refletância devido ao espalhamento nas diferentes camadas das folhas (BORATTO; GOMIDE, 2013). Dessa forma, os mapas apresentam as seguintes classes: água, solo úmido, solo seco, vegetação esparsa, vegetação mista e vegetação densa. Neste segmento, ao perceber nos mapas relativos à figura 8, pela localização do Açude Poço da Cruz os tons azuis e verde escuro principalmente no ano de 2019, o que indica um maior índice no volume de água e maior presença de dosséis vegetais, bem como no entorno do PIMOX, apesar das fortes estiagens, ambas comprovadas até início do ano 2019 nesta área. Já para o ano de 2003 se observa uma quantidade esparsa. Voltando ainda para o ano de 1995, há a menor presença visualmente perceptível de vegetação, aparecendo como destaque a vegetação esparsa, podendo essa ser identificada como caatinga.

Figura 8: Espacialização do NDVI no município de Ibimirim nos anos de 1995, 2003 e 2016.

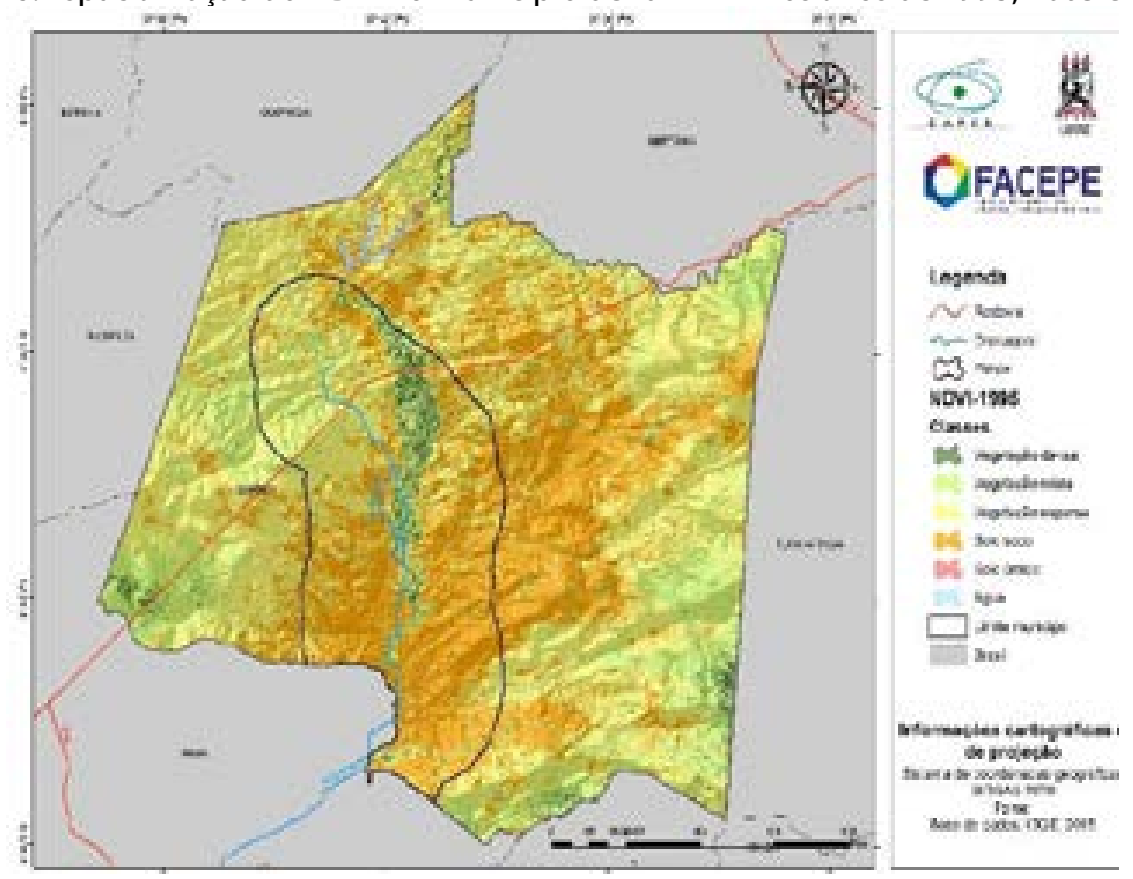





Fonte: Elaborado pelos autores.

Os valores referentes às classes observadas no NDVI podem ser melhor verificados no quadro 3 com maior rigor de detalhes. Realizando essa atividade de comparação entre as 3 datas escolhidas, é possível observar que em 1995 a classe que pode ser tida como de 
destaque é a vegetação esparsa, ficando com $878 \mathrm{Km}^{2}$ de área em Ibimirim, quanto a classe de água, a qual se configura os reservatórios com os recursos hídricos do município há uma espacialização de quase $6 \mathrm{Km}^{2}$. Outra classe com considerável relevância é a do solo seco, em $\mathrm{Km}^{2}$ sua área contou com $660 \mathrm{Km}^{2}$.

Quadro 2: Medidas de classes em extensão de áreas $\left(\mathrm{km}^{2}\right)$ pelo NDVI

\begin{tabular}{|l|l|l|l|}
\hline Classes & $\mathbf{1 9 9 5}$ & $\mathbf{2 0 0 3}$ & $\mathbf{2 0 1 9}$ \\
\hline Água & 5,91 & 4,59 & 12,66 \\
\hline Solo úmido & 1,92 & 10,92 & 45,63 \\
\hline Solo seco & 660,83 & 680,2 & 14,31 \\
\hline Vegetação esparsa & 878,7 & 845,93 & 334,78 \\
\hline Vegetação mista & 305,987 & 267,11 & 670,72 \\
\hline Vegetação densa & 52,54 & 97,15 & 700,72 \\
\hline
\end{tabular}

Fonte: Elaborado pelos Autores (2020).

No ano de 2003, a vegetação esparsa continua em sua predominância, embora exista alguma redução, com então $845 \mathrm{Km}^{2}$, o solo seco aumentou em comparação a data anterior com então $680 \mathrm{Km}^{2}$, e as águas superficiais no município de Ibimirim reduz em tamanho de área com 4,59 $\mathrm{Km}^{2}$. Para especificamente o ano de 2019 observa-se uma reconfiguração espacial, não só da vegetação, mas de todas as classes definidas para o presente estudo em Ibimirim, mostrando agora uma dinâmica diferente em relação as datas anteriores, a classe antes predominante, a da vegetação esparsa agora contou com $334 \mathrm{Km}^{2}$, enquanto que a classe predominante tornou-se a da vegetação densa, com $700 \mathrm{Km}^{2}$ e a classe de água agora configurou-se com $12 \mathrm{Km}^{2}$, quantia maior que os anteriores analisados.

4.5 Uso e cobertura da terra

Na figura 9 é possível verificar os mapas referentes ao uso e cobertura da terra nos anos de 1995, 2003 e 2016, onde espacialmente apresentaram diferenciações nas classes definidas nos dados do mapbiomas. 
Figura 9: Espacialização do uso e cobertura do solo nos anos de 1995, 2003 e 2016

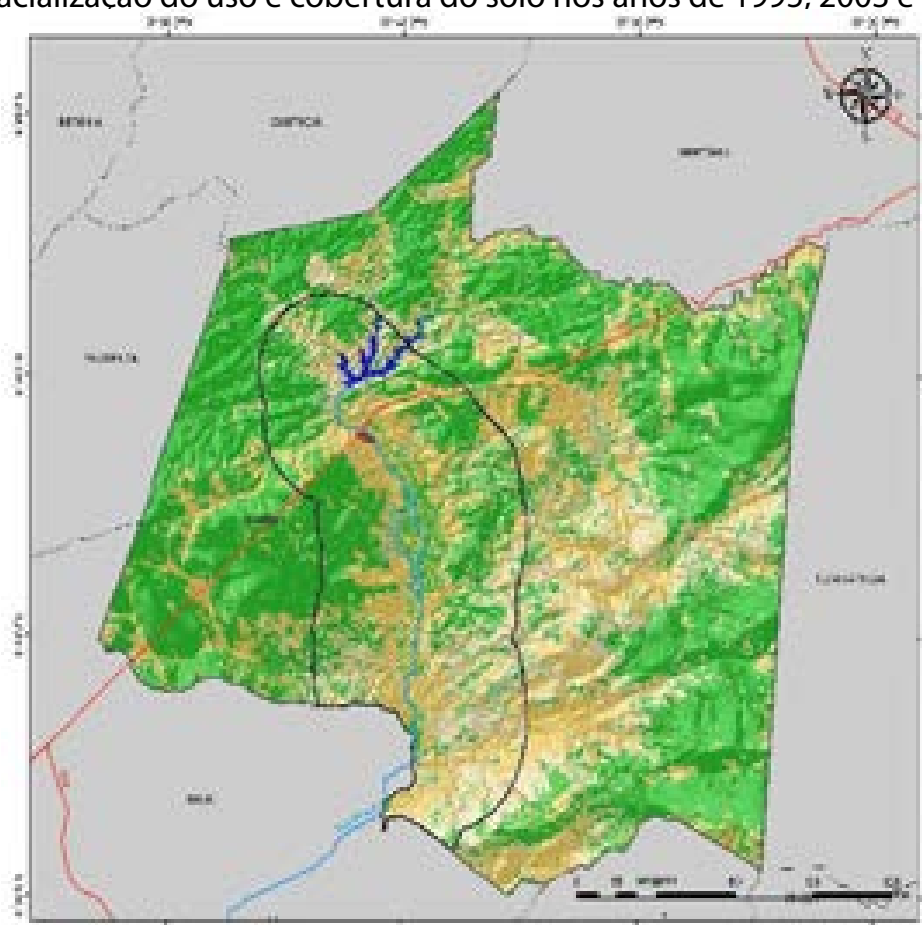

C. $\frac{4}{2}$
CFACEPE

Ligesde

Nones

Cormente

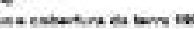

Cimens

ES canmere

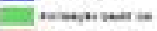

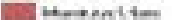

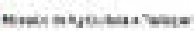



nower

$\square$ insone

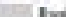

Inforsasbescantograncise de projectso

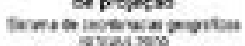
Pisce

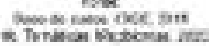

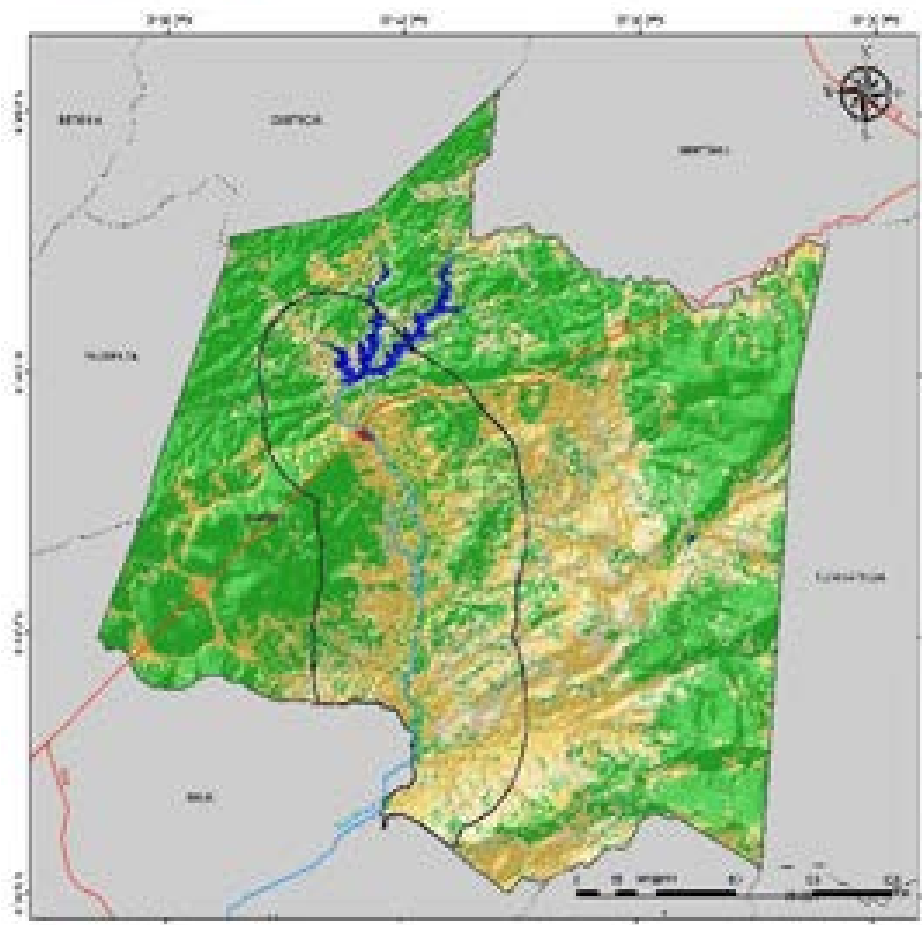

C... OFACEPE

brescle

N moose

20imese

C3 $\mathrm{mr}=$

Une 7 cocentary ca tera 280 ?

Cimina

inom:

달.

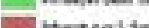

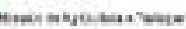

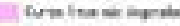

roven

$\square$ insorme

Ine

antorasobes catograncise de projecso
flewe






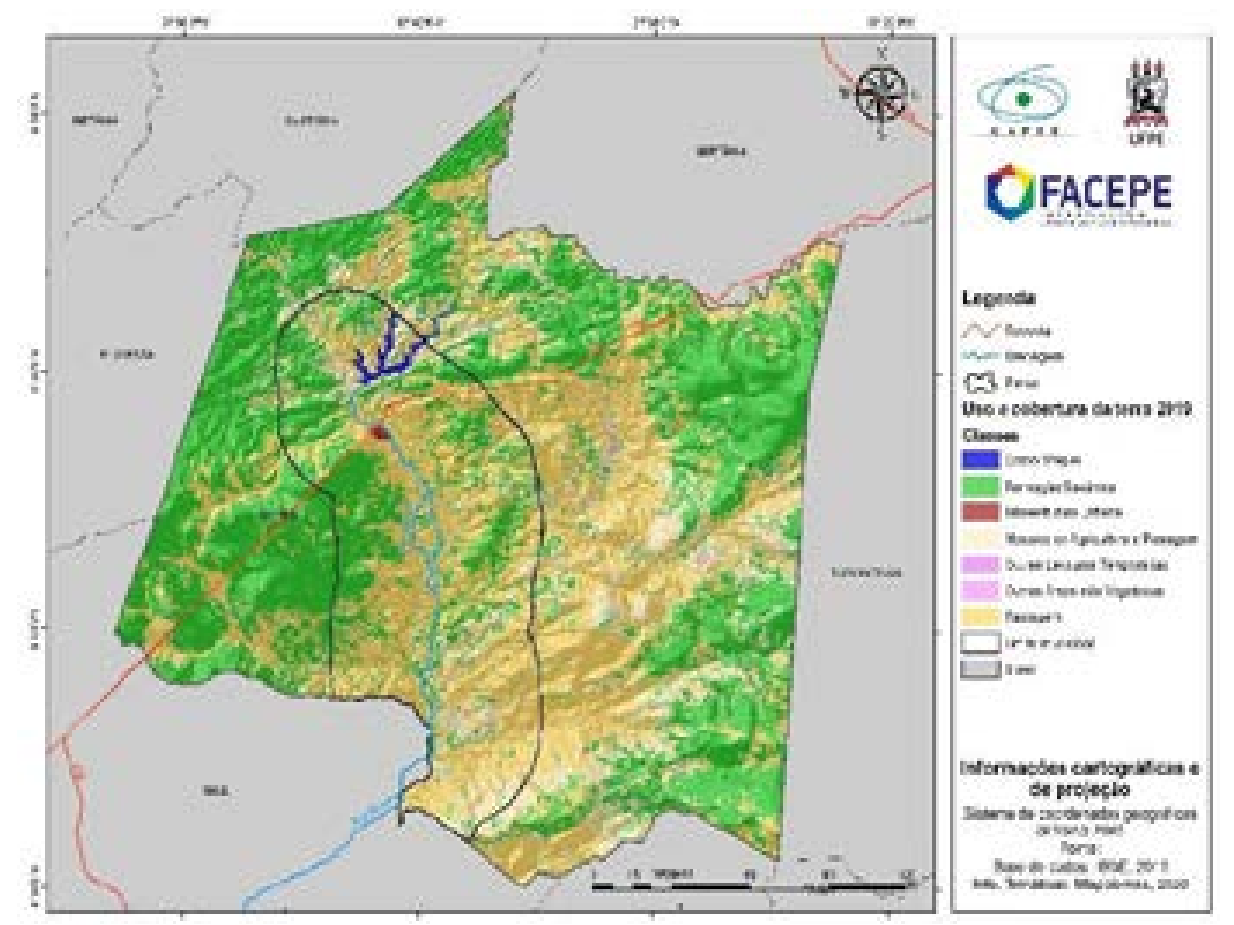

Fonte: Elaborado pelos autores.

De acordo com os dados apresentados no Quadro 3, percebeu-se a diminuição da classe formação savânica em todas as datas (1995, 2003, 2019), evidenciado a degradação contínua da cobertura vegetal, assim como a diminuição da representação da classe mosaico da agricultura e pastagem. Por outro lado, percebe-se o aumento da classe infraestrutura urbana, mostrando o aumento da expansão urbana no município de Ibimirim. Há diminuição nos corpos d'água entre os anos de 1995 e 2019, evidenciando as baixas precipitações de chuva.

Quadro 3: Medidas de classes de uso e cobertura da terra em $\mathrm{km}^{2}$

\begin{tabular}{|l|l|l|l|}
\hline Classes & 1995 & 2003 & 2019 \\
\hline Formação savânica & $1.059,28$ & $1.040,04$ & 872,344 \\
\hline Pastagem & 454,73 & 485,92 & 704.212 \\
\hline Mosaico Agricultura e pastagem & 383,58 & 361,638 & 319.509 \\
\hline Infraestrutura urbana & 0,972 & 1,099 & 1,561 \\
\hline Outras áreas não vegetadas & 0,089 & 0.089 & 1,514 \\
\hline Corpos d'água & 7,252 & 17,07 & 6,671 \\
\hline Formação florestal & & 0.0526 & \\
\hline Lavouras temporárias & & & 0,123 \\
\hline
\end{tabular}

Fonte: Elaborado pelos autores. 
Especificamente no ano de 1995, a classe com maior relevância por seu tamanho em área é a de vegetação savânica, que pode ser entendida como caatinga, portando aproximadamente $1.059 \mathrm{Km}^{2}$, em tamanho de cobertura, a classe de outras áreas não vegetadas (áreas sem vegetação ou degradadas), ficou com menos de $1 \mathrm{Km}^{2}$ de extensão. A classe com maior relevância dentre aquelas que são áreas antropicamente alteradas é a de pastagem, com $454 \mathrm{Km}^{2}$ dentro do perímetro de Ibimirim. Em 2003, considerando essas mesmas classes, é possível afirmar que houve uma diminuição na formação savânica, quando ela apresentou $1.040 \mathrm{Km}^{2}$ em sua área. As outras áreas não vegetadas permaneceram com menos de $1 \mathrm{Km}^{2}$, enquanto que a pastagem continuou a destacar-se como a área que foi antropicamente influenciada, crescendo para $485 \mathrm{Km}^{2}$. Para o ano de 2019 , houve um relevante decréscimo da formação savânica, ficando com $872 \mathrm{Km}^{2}$, enquanto que a classe de pastagem cresceu ainda mais, apresentando $704 \mathrm{Km}^{2}$, e para as outras áreas não vegetadas restou apenas $1,51 \mathrm{Km}^{2}$ de área.

\subsection{Quadro Situacional do Açude Poço da Cruz}

Em decorrência de grandes secas, a partir de 1993, e da má administração das águas, o açude atingiu níveis críticos, acumulando pouco mais de $74.000 .000 \mathrm{~m}^{3}$ de água, equivalente a menos de $15 \%$ de sua capacidade total de $504.000 .000 \mathrm{de} \mathrm{m}^{3}$ (SALIN, 2010). Como uma das estratégias para mitigação desta problemática, é necessário fortalecer os organismos voltados à gestão das águas, para que não haja retrocesso, além de se promover a capacitação de profissionais para atuarem nos comitês de bacia hidrográfica, dando suporte técnico ao seu funcionamento.

Em face de estiagem prolongada, o fornecimento do suprimento hídrico do açude foi suspenso em janeiro de 2014 em virtude de ele conter apenas 7\% de sua capacidade e as atividades do Pimox foram parcialmente paralisadas no mês de agosto de 2015. Segundo Aguiar (2019), o açude em 2015 se encontrava apenas com 6\% da sua capacidade, alcançou níveis nunca antes vistos, com a média abaixo do volume morto e a qualidade da água comprometida com a eutrofização.

O principal fator para a suspensão total da distribuição das águas do açude foi o baixo volume de águas, com apenas $20.000,00 \mathrm{~m}^{3}$ em dezembro de 2017 , o que corresponde a $4 \%$ da capacidade de armazenamento, volume que garante a sobrevivência da vida aquática existente (DNOCS, 2018), problema este percebido na figura 10. 
Figura 10. Situação do açude Poço da Cruz em julho de 2016 a montante da comunidade Poço da Cruz, município de Ibimirim - PE

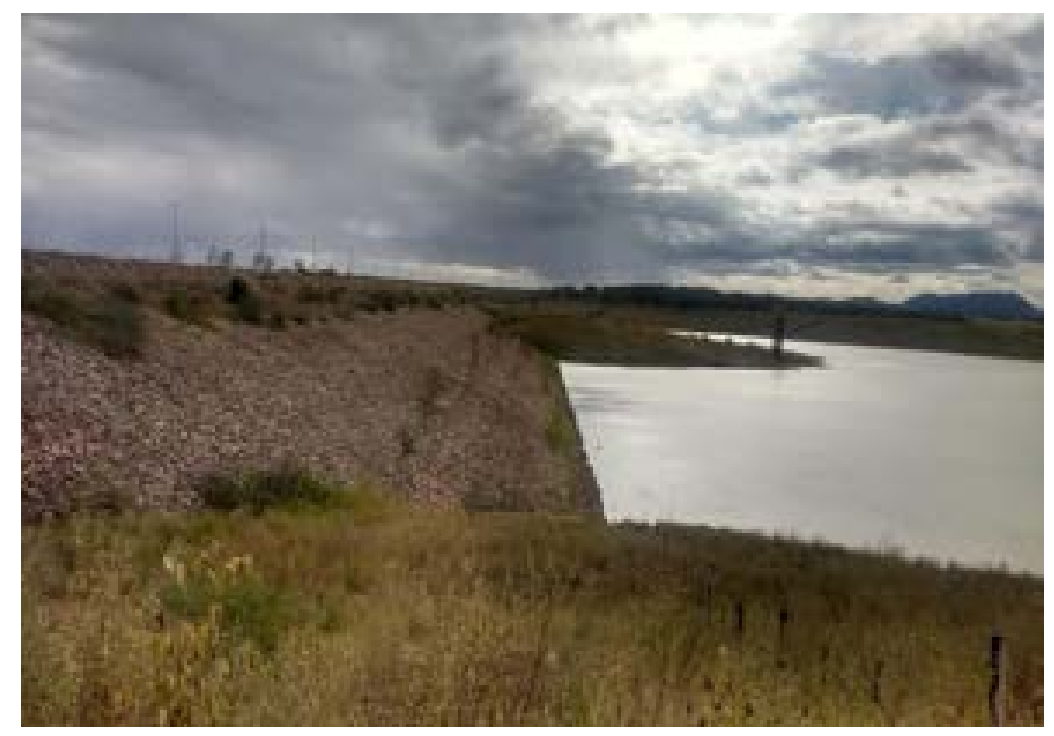

Fonte: Acervo dos autores.

A administração das águas do açude destinada à irrigação passou a ser de responsabilidade da Associação dos Produtores Rurais Irrigantes do Vale do Moxotó (Univale), com a direção do DNOCS. Entretanto, atualmente não mais existe o Convênio PGE 10/2003 celebrado entre o DNOCS e a Univale, que dava sustentação jurídica a esta gestão consorciada. Tal fato foi descrito por Santos (2018), devido ao colapso hídrico nos últimos anos a Univale deixou de administrar o açude. Assim, as atividades destinadas ao fornecimento, operação e manutenção do perímetro encontram-se sob a responsabilidade/ administração do DNOCS, uma vez que as decisões políticas sobre a utilização das águas do açude são tomadas pelo Conselho dos Usuários das Águas do Açude Poço da Cruz (Consul).

Em dezembro de 2016, dos 565 lotes situados ao longo do Perímetro Irrigado do Moxotó (Pimox), apenas 60 (sessenta) operavam através de água de poços, dando suporte a produção agrícola do município. No entanto, ressalta-se que atualmente $(2019,2020)$ os agricultores do PIMOX executam suas atividades agrícolas através de águas provenientes de poços artesianos por conta própria, sem acompanhamento técnico do DNOCS. Trabalhando com a aplicação do sensoriamento remoto no monitoramento do Açude Poço da Cruz, Costa (2019), pode-se constatar em relação gestão dos recursos hídricos deste açude que, 
O sistema hídrico formado pelo reservatório Poço da Cruz passou a contar com condições de uso dos recursos hídricos a partir da publicação da Resolução ANA n 54/2018, de 6 de agosto de 2018, que dispõe sobre condições de uso dos recursos hídricos no sistema, definindo a vazão média outorgável no reservatório. De acordo com a resolução, os usos da água do sistema ficam condicionados ao estado hidrológico do reservatório, que será determinado conforme o volume acumulado em maio de cada ano. Além disso, as alocações anuais de água serão realizadas em reuniões públicas coordenadas pela ANA em articulação com a APAC e com a Comissão Gestora do açude Poço da Cruz (COSTA, 2019, p. 79).

Atualmente (2020-2021), conforme mostrado na figura 11, o açude Poço da Cruz encontra-se com vazão satisfatória. Os irrigantes do PIMOX esperam uma atitude por parte do poder público no que tange a liberação das águas para darem início às atividades de agricultura irrigada e, sobretudo, suporte em relação à execução de tais agilidades no âmbito da produção agrícola para o desenvolvimento socioeconômico do município de lbimirim e região.

Figura 11. Situação do açude Poço da Cruz em dezembro de 2020, a montante da comunidade Poço da Cruz, município de Ibimirim - PE

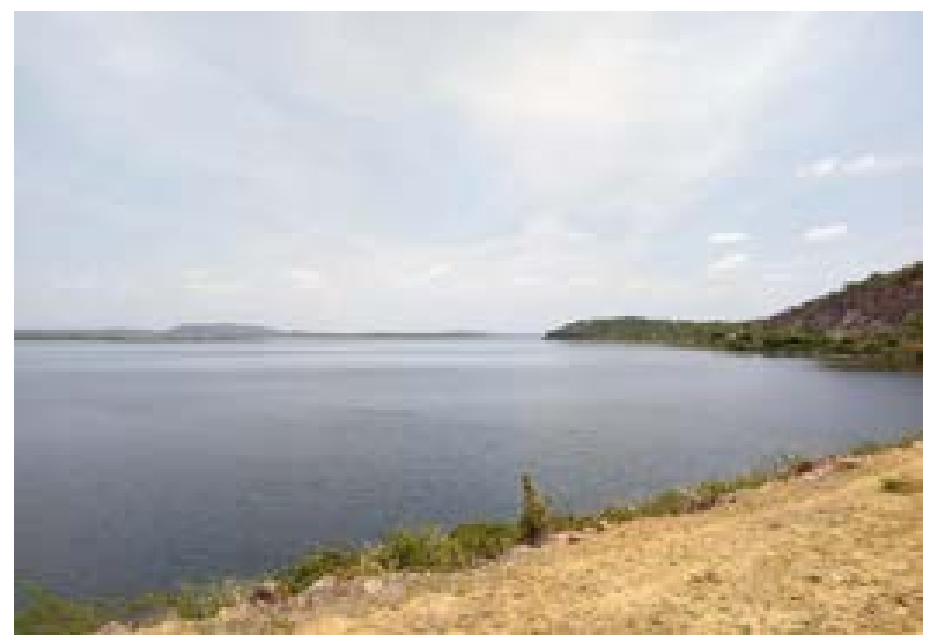

Fonte: Acervo dos autores.

\section{Considerações finais}

O Açude Público Federal Engenheiro Francisco Saboia é um relevante reservatório na região, especialmente para a comunidade de Poço da Cruz e Perímetro Irrigado do Moxotó (Pimox), contribuindo com o melhoramento da qualidade de vida e bem-estar local 
através da agricultura irrigada e ainda para convivência com o semiárido. Inexiste política educacional no sentido de sensibilizar os usuários, os agricultores e a população em geral acerca da preservação dos recursos naturais e especificamente dos irrigantes que usufruem da pouca água proveniente do açude. Para a manutenção da qualidade e quantidade das águas, visto que, nos últimos anos, tem registrado secas recorrentes. É indispensável a execução de uma educação ambiental com inclusão de técnicas eficientes e hábeis focadas no manejo conservacionista ou sustentável dos solos e água na gestão da irrigação de modo compreensivo, com laços entre o poder público, sociedade civil organizada e comunidade, para que todos os benefícios do açude sejam aproveitados de forma abrangente e em harmonia com o meio ambiente.

A adoção de tecnologias sofisticadas como as geotecnologias de sensoriamento remoto em consonância com as de meteorologia são de extrema acuidade para auxílio e orientação nas atividades de manejo e gestão da irrigação em açudes como o Eng. Francisco Saboia (Poço da Cruz) situado em Ibimirim, estado de Pernambuco, Brasil. Os mapas temáticos das imagens processadas com os dois índices de vegetação NDWI, NDVI simultaneamente, mais dados de uso e ocupação do solo, ambos avaliados para fins de gestão de água na irrigação e cobertura da terra na faixa que cobre toda extensão do município de Ibimirim, principalmente colunas d'água ou extensões úmidas existentes no reservatório Poço da Cruz, permitiram detectar e separar em diferentes classes de uso e cobertura do solo na região.

Diante da conjuntura pela qual se encontra as condições em relação a vazão e usos das águas do açude Poço da Cruz, revela-se, sine qua non, a implantação de políticas públicas voltadas para a utilização de tecnologias de captação e armazenamento de água das chuvas; participação de técnicos extensionistas (engenheiros agrônomos, técnicos agrícolas e técnicos em agroecologia) para auxiliarem no manejo da irrigação e de técnicas de convivência com o problema da salinidade na agricultura como, por exemplo, admissão de sistema de irrigação eficiente como o gotejamento.

\section{Agradecimentos}

Aos técnicos do Departamento Nacional de Obras Contra a Seca (DNOCS) e agricultores do Perímetro Irrigado do Moxotó (Pimox), no município de Ibimirim (PE), pela participação na pesquisa e a Fundação de Amparo à Ciência e Tecnologia do Estado de Pernambuco (FACEPE) pela bolsa concedida ao primeiro autor e disponibilizada para o 
estudo durante o biênio 2019-2021.

\section{Referências}

ABREU, W. W. N.; CALDEIRA, C. R. T.; CALDEIRA, M. C. O.; GRAÇA, A. J. S.; VICTORINO, H. S.; PONTES, P. S. V.; CEREJA, S. S. A.; PEREIRA, J. A. A.; CORREA, I. C. A.; SILVA, M. V. S. Extração vetorial automática de corpos hídricos a partir de imagens orbitais, utilizando a linguagem Python sobre o rio Paranapanema. Braz. J. of Develop., Curitiba, v. 6, n.5, p.24418-24439 may. 2020.

AGÊNCIA NACIONAL DE ÁGUAS (ANA). Boletim de Acompanhamento da Alocação de Água 201812019. Poço da Cruz. Disponível em: http://www.apac.pe.gov.br/down/not_1095_15470562455c363475bc3db_ boletim_de_acompanhamento_da_alocacao_poco_da_cruz_2018_2019__dezembro_2018.pdf. Acesso em: 06 out. 2019.

AGÊNCIA PERNAMBUCANA DE ÁGUAS E CLIMA (APAC). Boletim de acompanhamento de alocação de água 2017 -2018 - Açude poço da Cruz. 2016. Disponível em: http://www.apac.pe.gov.br/down/ not_1036_15166240075a65d88728ab1_boletim_acompanhamento_alocacao_2017_2018_reservatorio_ poco_da_cruz__dezembro2017.pdf. Acesso: 29 out. 2018.

AGÊNCIA PERNAMBUCANA DE ÁGUAS E CLIMA (APAC). Monitoramento pluviométrico. 2016. Disponível em: http://www.apac.pe.gov.br/meteorologia/monitoramento-pluvio.php . Acesso em: 11 jan. 2017.

AGUIAR, B. K. G. Análise de constelação em bacias hidrográficas no uso e ocupação do solo e da água nas margens do reservatório Poço da Cruz, Ibimirim, Pernambuco, Brasil. 2019. 68 f. Monografia (Graduação em Tecnologia em Gestão Ambiental), Instituto Federal de Educação, Ciência e Tecnologia de Pernambuco. Recife.

ALBUQUERQUE, A. M..; RIBEIRO, J R. C.; SALES, M. C. L. A aplicação do índice de vegetação por diferença normalizada (NDVI) para análise da degradação ambiental da área de influência direta do açude Castanhão. Revista da Casa da Geografia de Sobral, Sobral/CE, v. 21, n. 2, Dossiê: Estudos da Geografia Física do Nordeste brasileiro, p. 674-685. 2019.

AMORIM, R. F.; ALMEIDA, S. A. S.; CUELLAR, M. Z.; COSTA, A. M. B.; GOMES, C. Mapeamento de Uso e Ocupação do solo na Bacia Hidrográfica Piranhas/Açu, utilizando imagens CBERS e técnicas de classificação supervisionada. Anais XIII Simpósio Brasileiro de Sensoriamento Remoto, Florianópolis, Brasil, 21-26 abril 2007, INPE, p. 51595166.

ASFAW, E.; SURYABHAGAVAN, K. V.; ARGAW, Mekuria Soil salinity modeling and mapping using remote sensing and GIS: The case of Wonji sugar cane irrigation farm, Ethiopia. Journal of the Saudi Society of Agricultural Sciences, v. 17, Issue 3, p. 250-258. 2018.

AZEVÊDO, A. C. Verso e Reverso das Políticas Públicas de Água para o Semiárido Brasileiro. Rev. Política e Planej. Reg., v. 2, p. 373-392, 2015.

BACALHAU, J. R.; NETO, A. R.; OLIVEIRA, L. M. M. Aplicação de índice de vegetação no monitoramento da seca: Açude Algodões no Sertão pernambucano. Journal of Environmental Analysis and Progress. Recife. v. 2, n. 3, p. 283-293. 2017.

BALLÉN, L. A. C.; SOUZA, B. I.; LIMA, E. R.V. Análise espaço-temporal da cobertura vegetal na área de proteção ambiental do Cariri, Paraíba, Brasil. Boletim Goiano de Geografia. v. 36, n. 3, set/dez. 2016.

BATISTA, V. H. A. Monitoramento de variáveis hidrológicas e vegetação em bacia do Semiárido Pernambucano. 2018. 42 f. Relatório de Estágio Supervisionado Obrigatório (Graduação em Engenharia Agrícola e Ambiental) Universidade Federal Rural de Pernambuco. Recife, 2018. 
BORATTO, I. M. P.; GOMIDE, R. L. Aplicação dos índices de vegetação NDVI, SAVI e IAF na caracterização da cobertura vegetativa da região Norte de Minas Gerais. Anais XVI Simpósio Brasileiro de Sensoriamento Remoto - SBSR, Foz do Iguaçu, PR, Brasil, 13 a 18 de abril de 2013, INPE.

CARVALHO, A. A. D.; MONTENEGRO, A. A. D. A.; SILVA, H. P. D.; LOPES, I.; DE MORAIS, J. E.; DA SILVA, T. G. Trends of rainfall and temperature in Northeast Brazil. Revista Brasileira de Engenharia Agrícola e Ambiental, v. 24, p. 15-23, 2019.

COELHO, E. F.; FILHO, M. A.C.; OLIVEIRA, S.L. Agricultura Irrigada: eficiência de irrigação e uso de água. Revista Bahia Agrícola. v.7, n.1, p. 57-60, 2005.

COSTA, F. A. Sensoriamento remoto aplicado ao monitoramento de reservatório no semiárido do Nordeste: Poço da Cruz (Pernambuco). 2019. 110 f. Dissertação (Mestrado). Programa de Pós-Graduação em Gestão e Regulação de Recursos Hidricos, Centro de Tecnologias e Geociências, Universidade Federal de Pernambuco. Recife, 2019.

CUNHA, C. F.; CARDOSO, S. B.; TERAMOTO, E. H.; CHANG, H. K.; Modelo área-volume para a represa Guarapiranga empregando o índice NDWI. Holos Environment, Rio Claro, v. 20 n. 1: p. 137-151. 2020.

DNOCS- Departamento Nacional de Obras Contra as Secas. Perímetro Irrigado Moxotó. Disponível em:<https://www.dnocs.gov.br/ dnocs/doc/canais/perimetros_irrigados/pe/moxoto.htm. Acesso em: 29. Outubro 2018.

DUQUE, J.G. Solo e água no Polígono das Secas. 3.ed. Mossoró, RN: ESAM,1980. (Coleção Mossoroense, v.142).

EMBRAPA. Empresa Brasileira de Pesquisa Agropecuária - ZAPE. 2002. Zoneamento agroecológico do Estado de Pernambuco. Recife: Embrapa, Solos UEP Recife/SPRRA-PE.

EMBRAPA. Empresa Brasileira de Pesquisa Agropecuária. Objetivos de Desenvolvimento Sustentável 6: Água e saneamento - Contribuições da Embrapa. Brasília, DF 2018.

Explorador de Água na Superfície. Global Surface Water Explorer. Disponível em: (global-surface-water. appspot.com). Acesso em: 26 mar. 2021.

FINCH, J.W. Monitoring Small dams in semi-arid regions using remote sensing and GIS. Journal and Hidrology, v. 195, n.1-4, p. 335-351. 1997.

FREIRE, M. B. G. S.; MIRANDA, M. F. A.; OLIVEIRA, E. E. M.; SILVA, L. E; PESSOA, L. G. M.; ALMEIDA, B. G. Agrupamento de solos quanto à salinidade no Perímetro Irrigado de Custódia em função do tempo. Revista Brasileira de Engenharia Agrícola e Ambiental, Campina Grande, v. 18, suplemento, p. 586-591. 2014.

GAO, B.-C. NDWI - A Normalized Difference Water Index for remote sensing of vegetation liquid water from space. Remote Sensing of Environment, v. 58, p. 257-266, 1996.

GARCIA, A. C. S. M.; FILHO, J. C. A.; SILVA, H. P. S. P.; CARVALHO, R. M. C. M. O. Estudo espaço temporal de áreas susceptíveis a desertificação do semiárido brasileiro. Revista Gestão e Sustentabilidade Ambiental. Florianópolis, v. 8. n. 3, p. 352-370. 2019.

HU, J.; WU, J.; QU, X.; LI, J. Effects of organic wastes on structural characterizations of humicacid insemiarid soil under plastic mulched drip irrigation. Chemosphere, v. 200, June 2018, p. 313-321.

HUANG, M.; JIANG, D.; ZHANG, M.; HUANG, Y.Increasing aridity affects soil archaeal communities by mediating soilniches in semi-arid regions. Science of The Total Environment, v. 647, n. 10, p. 699-707. 2019.

INSTITUTO NACIONAL DE METEOROLOGIA (INMET) Disponível em: http://www.inmet.gov.br/portal/index. php?r=tempo/graficos. Acesso em: 29 de Outubro 2018. 
KNÜPPE, K.; MEISSNER, R. Drivers and barriers towards sustainable water and land management in the OlifantsDoorn Water Management Area, South Africa, v. 20, p. 3-14. 2016.

LIMA, N. A. S.; OLIVEIRA, L. M. M.; XAVIER, M. L. P.; JUNIOR, U. J. S.; NASCIMENTO, E. F. Spectral Indices for remote sensing with the LANDSAT-5 and SENTINEL-2 satellites around the Poço Cruz reservoir-PE. Journal of Hyperspectral Remote Sensing. Recife. v. 9, n. 5, p. 299-309. 2019.

LOPES I.; SANTOS, S. M.; LEAL, B. G.; MELO, J. M. M. Variação do índice de aridez e tendência climática à desertificação para a região semiárida do nordeste brasileiro. Revista Brasileira de Geografia Física. Recife, v. 10, n. 4, p. 1014-1026. 2017.

LUO, S.; WANG, S.; TIAN, L.; SHI, S.; TIAN, C. Aggregate-related changes in soil microbial communities under different ameliorant applications in saline-sodic soils. Geoderma, v. 329, n.1, p. 108-117. 2018.

MAPBIOMAS. Plataforma de mapas e dados. Disponivel em: https://Mapbiomas Brasil. Acesso em: 23 mar. 2021.

MARCUZZO, F. N, ANDRADE, L. R.; MELO, D. C. R. Métodos de Interpolação Matemática no Mapeamento de Chuvas do Estado do Mato Grosso. Revista Brasileira de Geografia Física, v. 4, n. 4, p. 793-804. 2011.

MELO, C.R. Análise do eixo leste da transposição do Rio São Francisco face aos cenários de uso previsto. 2010. 201 f. Dissertação (Mestrado). Programa de Pós-Graduação em Engenharia Civil, Centro de Tecnologias e Geociências, Universidade Federal de Pernambuco. Recife

MERONI, M.; NG, W-T.; REMBOLD, F.; LEONARDI, U.; ATZBERGER, C.; GADAIN, H.; SHAYE, M. Mapping Prosopis juliflora in west Somaliland with Landsat 8 satellite imagery and ground information. Land Degradation \& Development, v. 28, p. 494-506. 2017.

MORA, J. L.; HERRERO, J.; WEINDORF, D. C. Multivariate analysis of soil salination-desalination in a semi-arid irrigated district of Spain., v. 291, n. 1, p. 1-10. 2017.

OBERMAIER, M. Velhos e Novos dilemas nos sertões: Mudanças Climáticas, Vulnerabilidade e Adaptação no Semiárido Brasileiro. 2011. 167 f. Tese (Doutorado em Planejamento Energético) - Universidade Federal do Rio de Janeiro, Rio de Janeiro, 2011.

OLIVEIRA, A. M; DIAS, N. S; FREITAS, J. J. R.; Martins, D. F. F; RABELO, L. N. Avaliação físico-química das águas do processo de dessalinização de poços salobros e salinos em comunidades rurais do oeste potiguar. Revista Águas Subterrâneas. São Paulo. v. 31 n², p.58-73. 2017.

OLIVEIRA, L. B. Uso e manejo da água na região semiárida do Nordeste do Brasil. In. Anais da Academia Pernambucana de Ciência Agronômica, Recife, v. 11/12, p.50-64. 2014/2015.

PERUZZO, J. S.; PEREIRA, M. C. S.; SILVA, L. D. R.; OLIVEIRA, B. S.; SILVINO, G. S. Sensoriamento remoto aplicado ao monitoramento ambiental da bacia do Alto Piranhas, Semiárido Nordestino (Brasil). Revista Brasileira de Meio Ambiente, Recife, v. 7, n. 3, p. 028-037. 2019.

PESSOA, M. F., ASSIS, L. F., VIEIRA, A. S. Planejamento ótimo da água na agricultura irrigada: um estudo de caso em um perímetro paraibano. Revista Ibero-Americana de Ciências Ambientais, Aracajú, v. 7, n. 1, p. $221-234$. 2016.

RODRIGUES, M. T.; RODRIGUES, B. T.; TAGLIARINI, F.S. N.; CARDOSO, L. G.; CAMPOS, S. Desempenho e acurácia dos SIGs Terra View e Idrisi e seus respectivos classificadores supervisionados. Anais do XVIII Simpósio Brasileiro de Sensoriamento Remoto. Santos, p. 2263-2270, 2017.

SALIN, T. C. Caracterização de sistemas de produção no município de lbimirim, região semiárida de Pernambuco: 
as bases para um planejamento agroflorestal. $124 \mathrm{f}$. Dissertação (Mestrado em Ciências Florestais) Departamento de Ciência Florestal, Universidade Federal Rural de Pernambuco. Recife, 2010.

SÁNCHEZ-MORENO, S.;CANO, M.;LÓPEZ-PÉREZ, A.;BENAYAS, J.M. R. Microfaunal soilfood webs in Mediterranean semi-arid agroecosystems. Does organic management improve soil health? Applied Soil Ecology, v. 125, p. 138-147. 2018.

SANTOS, C. C. P.; COELHO, F. N.;TEIXEIRA, C. P.T.; Neto, L. B. L.; SILVA MATOS, S. A. O uso da técnica Phansharpening em imagens Landsat 8 para identificação do calor superficial em aglomerados Urbanos. Anais $6^{\circ}$ Simpósio de Geotecnologias no Pantanal, Cuiabá, p. 104 -112, 2016.

SANTOS, T. C. G. Avaliação de impactos, vulnerabilidades e estratégias de adaptação às mudanças climáticas no semiárido pernambucano; estudo de caso do APL de agricultura familiar no Perímetro Irrigado do Moxotó - PIMOX, Sertão do Moxotó (Ibimirim - PE). 2018. 80 f. Dissertação (Mestrado). Programa de Pós-Graduação em Engenharia Ambiental, Universidade Federal Rural de Pernambuco. Recife.

SERVIÇO NACIONAL DE APRENDIZAGEM RURAL (SENAR). Irrigação: gestão de água e energia elétrica. Brasília: Coleção Senar, 255. Brasília-DF, 2019.

SHIFERAW, H.; BEWKET, W. B.; ALAMIREW A. T.; ZELEKE, G. A.; TEKETAY, D. C.; BEKELE, K. D.; SCHAFFNER U. E.; ECKERT F. S. Implications of land use/land cover dynamics and Prosopis invasion on ecosystem service values in Afar Region, Ethiopia. Science of The Total Environment. n. 675. p. 364-366. 2019.

SILVA, V. B. Diagnóstico da desertificação no município de Ibimirim-PE. 88f. 2006. Dissertação (Mestrado). Programa de Pós-Graduação em Desenvolvimento e Meio Ambiente, Universidade Federal de Pernambuco, Recife.

SULIMAN, M.; NAWATA, H.; HOSHINO, B.; KARAMALLA, A. Mesquite Risk Mapping and Assessment in Tokar Delta-Eastern Sudan. Journal of Nature Resourses \& Environmental Studies, v. 3, n. 1, p. 9-13. 2015.

TAVARES FILHO, A. N. Níveis da necessidade de gesso sobre as características físico-químicas e na correção de solos salino-sódicos do Perímetro Irrigado de Ibimirim - PE. 81 f. 2010. Dissertação (Mestrado). Programa de Pós-Graduação em Engenharia Agrícola, Departamento de Tecnologia Rural, Universidade Federal Rural de Pernambuco. Recife.

TAVARES, V. C.; ARRUDA, I. R. P.; SILVA, D. G. Desertificação, mudanças climáticas e secas no semiárido brasileiro: uma revisão bibliográfica. Geosul, Florianopolis, v. 34, n. 70, p. 385-405,. 2019.

USGS - United States Geological Survey. Landsat 8 (L8) Data Users Handbook. Unite States Department of the Interior. 2016. $98 \mathrm{p}$.

VALLADARES, G. S.; FARIA, A. L. SIG na análise do risco de salinização na bacia do rio Coruripe, AL. Engevista, v. 6, n. 3, p. 86-98, 2004.

ZHANG, M.; DONG, B.; QIAO, Y.; YANG, H.; WANG, Y.; LIU, M. Effects of sub-soil plastic film mulch on soil water and salt content and water utilization by winter wheat under different soil salinities. Field Crops Research, v. 225, p. 130-140, 2018. 